\title{
The relevance of larval biology on spatiotemporal patterns of pathogen connectivity among open-marine salmon farms
}

Danielle Cantrell, Ramón Filgueira, Crawford W. Revie, Erin Rees, Raphael Vanderstichel, Ming Guo, Michael G.G. Foreman, Di Wan, Jon Grant

D. Cantrell: Department of Health Management, Atlantic Veterinary College, University of Prince Edward Island, 550 University Ave, Charlottetown, PE, Canada, C1A4P3.

Email: dlburnett@upei.ca

R. Filgueira: Marine Affairs Program, Dalhousie University, 6299 South St, Halifax, NS, Canada, B3H 4R2 Email: Ramon.Filgueira@dal.ca

C.W. Revie: i) Department of Health Management, Atlantic Veterinary College, University of Prince Edward Island, 550 University Ave, Charlottetown, PE, Canada, C1AP3.

ii) Department of Computing and Information Sciences, University of Strathclyde, 26 Richmond Street, Glasgow, G1 1XQ, Scotland, UK

Email: crawford.revie@strath.ac.uk

E. Rees: i.) Department of Health Management, Atlantic Veterinary College, University of Prince Edward Island, 550 University Ave, Charlottetown, PE, Canada, C1AP3.

ii.) Land and Sea Systems Analysis, 14 rue Long, Granby, QC, Canada, J2G 6S8

Email: erinerees@gmail.com

R. Vanderstichel: Department of Health Management, Atlantic Veterinary College, University of Prince Edward Island, 550 University Ave, Charlottetown, PE, Canada, C1A4P3.

Email: rvanderstichel@gmail.com

M. Guo: Institute of Ocean Sciences, Fisheries and Oceans Canada, 9860 W Saanich Rd, Sidney, BC, V8L5T5 Email: mingguo88@gmail.com

M.G.G. Foreman: Institute of Ocean Sciences, Fisheries and Oceans Canada, 9860 W Saanich Rd, Sidney, BC, V8L5T5 Email: Mike.Foreman@dfo-mpo.gc.ca

D. Wan: Institute of Ocean Sciences, Fisheries and Oceans Canada, 9860 W Saanich Rd, Sidney, BC, V8L5T5 Email: Di.Wan@dfo-mpo.gc.ca

J. Grant: Department of Oceanography, Dalhousie University, 6299 South St, Halifax, NS, Canada, B3H 4R2 Email: jon.grant@dal.ca

Corresponding author: Danielle Cantrell, Department of Health Management, Atlantic Veterinary College, University of Prince Edward Island, 550 University Ave, Charlottetown, PE, Canada, C1A4P3.

Keywords: larval dispersal, connectivity, sea lice, biophysical modeling, aquatic epidemiology 


\begin{abstract}
Warming waters are changing marine pathogen dispersal patterns and infectivity worldwide. Coupled biological-physical modelling has been used in many systems to determine the connectivity of vulnerable meta-populations via infectious disease particles. Here we model the connectivity of sea lice larvae (Lepeophtheirus salmonis) among salmon farms in the Broughton Archipelago, British Columbia, Canada, using a coupled biological-physical model. The physical model simulated pathogen dispersal, while the biological component influenced the survival and developmental rates of the sea lice. Model results predicted high temporal variability in connectivity strength among farms; an emergent effect from the interacting parts of the simulation (dispersion vs. survival/development). Drivers of temporal variability were disentangled using generalized additive modeling, which revealed the variability was most strongly impacted by the spring freshet event, which can act as a natural aid for sea lice control in the Broughton Archipelago. Our results suggest that farm management strategies can benefit by taking into account short-term spikes in regional pathogen connectivity among farms. Additionally, future scenarios of a warming climate with reduced snowpack will likely make sea lice control more challenging.
\end{abstract}

\title{
Introduction
}

Transmission of water-borne pathogens (parasites, viruses, bacteria) in marine environments depends on factors influencing the movement and viability of the pathogen. Passive dispersal depends on local hydrodynamics, as dictated by winds, salinity gradients arising mainly from freshwater discharges, air-sea heat exchanges, and/or tidal forcing (Foreman et al. 2009). Some pathogens, particularly parasites with a free-living larval stage, possess some movement capabilities. For example, several species of parasitic nematodes (a phylum of generally parasitic 
round worms) have a free swimming larval stage and several intermediate hosts before ultimately infecting marine mammals or, in some cases, humans (Lunneryd et al. 2015). Sea lice, an ectoparasite of commercially and ecologically important fish species (Jones et al. 2006; Costello 2006), also possess a free-swimming larval stage, that influences their horizontal dispersal abilities (North et al. 2008; Johnsen et al. 2016); however, they are still largely dependent on local hydrodynamics for large scale (i.e. on the scale of kilometers) dispersal.

Additionally, the ability of water-borne pathogens to infect or infest a host can be influenced by the physical properties of the water they encounter, which can impact the growth, survival, and/or maturation of the pathogen (Brooker et al. 2018). For example, viruses will eventually degrade under ultraviolet B exposure (Jacquet and Bratbak 2003); bacterial or fungal pathogens can become spores in unfavourable abiotic conditions, to become infectious later in conditions more suited to their survival (Lennon and Jones 2011); temperature can impact bacterial replication rates and temperature stress can make hosts more susceptible to bacterial infection (Holt et al. 1989), and parasitic larvae development and survival rates are dependent on the water salinity and temperature they encounter (Groner et al. 2016a; Samsing et al. 2016). In addition, in order for a potential host to be vulnerable to contracting a water-borne pathogen, the host must come into contact with a sufficient dose of viable pathogen (Schmid-Hempel and Frank 2007). However, the role that any of these processes involved in pathogen dispersion and viability may play in disease transmission is difficult to determine.

Previous studies on water-borne disease transmission have frequently neglected important aspects related to the multifactorial nature of pathogen dispersion. For example, they often lack the circulation component, using laboratory studies to isolate how individual components contribute to a successful infection of a host independent of specific regional conditions. Population 
scale/epidemiological studies often use sea-way distance as a proxy for circulation (Aldrin et al. 2013; Rees et al. 2015). Studies that have explicitly modeled regional circulation (Stucchi et al. 2011; Adams et al. 2012; Asplin et al. 2014; Kough et al. 2015; Johnsen et al. 2016; Kragesteen et al. 2017; Salama et al. 2017; Samsing et al. 2017) typically do not elucidate the contributions of individual drivers to infectious pressure experienced by potential hosts.

The difficulty in determining epidemiologically important drivers of marine pathogen transmission in real aquatic populations experimentally or observationally has led to the increasingly common usage of computer simulations (Stucchi et al. 2011; Adams et al. 2012; Asplin et al. 2014; Kough et al. 2015; Johnsen et al. 2016; Kragesteen et al. 2017; Salama et al. 2017; Samsing et al. 2017; Arnold et al. 2017; Skarðhamar et al. 2018). These marine pathogen epidemiological simulations often include: a physical circulation model, a simulated release of particles to be carried by/move in the circulation (known as a particle tracking model), and a biological model of the lifecycle of the disease assigned to the simulated particles. When all three models are simulated in sequence, this can be referred to as coupled bio-physical modelling. Here, we apply a coupled bio-physical model to the salmon farm, sea-lice system, with the ultimate aim of quantitatively determining which physical drivers lead to farms experiencing increased infective dose from their neighbouring farms.

Sea lice are a naturally occurring ectoparasite that affect salmon farming productivity and the health of wild salmonids (Revie et al. 2003; Jansen et al. 2012; Kristoffersen et al. 2014; Rees et al. 2015). In the northern hemisphere, Lepeophtheirus salmonis is the species of greatest concern (Costello 2006), though other species, such as the more generalists Caligus clemensi can also cause infestations. Sea lice attach to the scales of salmonids, and feed on the scales, mucus, and blood of their hosts (Costello 2006). In adult fish, infestations can result in reduced feeding 
behaviours (and thus growth), as well as make them susceptible to secondary infections (Mustafa et al. 2000; Wagner et al. 2008). In juvenile fish, infestations can result in death due to osmoregulatory failure (Brauner et al. 2012; Patanasatienkul et al. 2013), though the levels required to consider a juvenile to be 'at risk' have rarely been reported over the past decade (C.W. Revie, pers comm). While the exact threshold size where juveniles are susceptible varies by species, generally they are most susceptible when smaller than 1 gram (Jones and Hargreaves 2009).

L. salmonis have several free-living larval stages after hatching, which can widely disperse, and are usually located in the upper layer of the water column (less than five $m$ of depth) (Johnsen et al. 2014). They do not become infectious and able to attach to a host until molting from nauplii into copepods (Boxaspen 2006). The egg production, maturation rate, and survivorship of sea lice are all dependent on the environmental conditions the louse encounters (Stucchi et al. 2011; Groner et al. 2016a; Samsing et al. 2016). For example, warmer temperatures result in shorter maturation time from larvae to maturity. Water below salinity thresholds results in death of the larvae or reduced ability to settle on a host fish. What the threshold precisely is has not yet been agreed on in the literature and likely varies between larval stages. However, Groner et al.'s 2016 metaanalysis on salinity's impact on sea lice survival found a general trend of decreasing survival with decreasing salinity, with 20 psu resulting in larval death (Groner et al. 2016a). The high fecundity and wide larval dispersal capabilities of the sea lice life cycle benefit their overall survival and success (Brooker et al. 2018).

A detailed understanding of sea lice dispersion and viability, and pathogens in general, should inform aquaculture disease management practices (Groner et al. 2016b). For example, farmed 
salmon are subject to viruses, bacteria, and parasites requiring expensive treatments or large scale culls (Murray and Peeler 2005). Treatments have economic and environmental costs associated with their use to control disease outbreaks, and resistance to such treatments is a growing concern worldwide for nearly all farmed salmon pathogens (Lees et al. 2008; Grøntvedt et al. 2014; Aaen et al. 2015; McEwan et al. 2015). Farm-to-farm transmission of pathogens is common in some areas, where connected clusters of farms must be treated together, or else re-infection is likely. This has been most well studied in European farming areas (i.e. Scotland and Norway) (Adams et al. 2012, 2015; Stene et al. 2014; Murray and Gubbins 2016; Samsing et al. 2017). Additionally, there is concern over the potential for farms to amplify and introduce diseases at higher densities to wild salmonid populations (Dill 2011; Kristoffersen et al. 2018; Nekouei et al. 2018).

Understanding connections among farms via pathogen transmission, and which environmental factors contribute to periods of larger infective pressure can help industry coordinate regional disease interventions as epidemiologically sensible management areas (e.g. groups of farms that need to be treated as a single unit to minimize outbreak potential) (Aldrin et al. 2013; Adams et al. 2015; Samsing et al. 2017). Selecting the correct spatial and temporal resolution for management of treatments, stocking/fallowing timing (Adams et al. 2016), and planning of future site locations is crucial for continued aquaculture sustainability, for quality and quantity of animal production, and for environmental sustainability to reduce the impact of pathogen spill-over to neighbouring wild fish populations (Krkosek et al. 2013) .

In this study we use a coupled bio-physical model to disentangle factors affecting sea lice dispersion and viability in a salmon farming coastal region that is also home to wild salmon populations: the Broughton Archipelago (BA) of British Columbia (BC), Canada. We investigated 
the difference in the strength of the connectivity among farms via infectious sea lice larvae under four different simulations, with increasing complexity in the biological model.

The population level patterns were then explored using generalized additive modelling (GAM) to elucidate the drivers of temporal variability in the infective dose farms exert on each other. This analysis also assessed whether drivers of temporal variability in the connectivity of farms varied spatially.

\section{Methods}

Study site and simulation period

The model domain is the BA, BC, Canada (Fig. 1); a group of islands off the northeastern tip of Vancouver Island. It is the site of a currently active salmon farming industry, as well as an important part of juvenile wild salmonid migratory routes for Pink (O. gorbuscha), Coho ( $O$. kisutch), and Chum salmon (O. keta), and to a much lesser extent, Sockeye (Oncorhynchus nerka) and Chinook (O. tshawytscha). It is a highly complex and fjordic area, with currents driven by tides, winds, and freshwater runoff from rivers whose discharges generally peak in the spring (Foreman et al. 2015) . Channels are as deep as $600 \mathrm{~m}$, though most range between 50-300 m (Foreman et al. 2006), and sea surface temperatures have a narrow range, from an average of 7.1C in January to 10.9 in August (Rogers et al. 2013).

The underlying physical model was constructed using the Finite Volume Community Ocean Model (FVCOM ) framework (Chen et al. 2003), began on March $1^{\text {st }}$, and was allowed a ten-day "ramp up" period for the currents to stabilize. The bio-physical simulation period therefore began 
March $11^{\text {th }}$, and ran to July $31^{\text {st }}, 2009$. The March-July time frame was chosen because this is the period during which the wild juvenile salmon will typically out-migrate from the rivers in which they were spawned to the open ocean.

\section{The bio-physical model}

The underlying circulation model is an update of that described in Foreman et al. (2009) to include air-sea heat exchanges. These exchanges have four components: sensible heat flux (differences in temperature between the air and water), latent heat flux (heat arising in changes between states, such as evaporation), short wave radiations (e.g. solar, some of which may be absorbed by clouds as well as ground and water), and long wave radiation (i.e. energy that the ground and water reemit back to the air).

The model domain is shown in Foreman et al. 2009, Fig. 1. There were 21 vertical gridded layers with variable spacing from sea bottom to surface, with the highest resolution at the surface and bottom layers, and maximum inter layer spacing of $9 \%$ of the depth at mid column. Depth ranged between $3 \mathrm{~m}$ and $520 \mathrm{~m}$ (Cantrell et al. 2018). Daily freshwater river discharge values were used (see Fig. 1 for river locations). M2, N2, S2, K1, P1, and O1 tidal constituents were prescribed as forcing at the model boundaries, and hourly tidal data was used. Hourly wind forcing data was captured with 9 weather stations deployed across the BA, with winds interpolated between and extrapolated beyond station locations to all grid elements (Foreman et al. 2009). The FVCOM physical circulation model outputs (i.e. wind, temperature, and salinity fields, and resulting currents) were validated by comparing model and observed tidal harmonics and calculating correlation coefficients between observed and modeled currents at several different depths at five separate weather stations across the BA for two weeks in late March, 2008. There was relatively 
good agreement, with the correlation coefficient worst at $4.5 \mathrm{~m}(0.74)$, and improving with depth, to a correlation coefficient of 0.94 at $130 \mathrm{~m}$ depth (Foreman et al. 2009).

Hourly output from the hydrodynamic model was used by an offline particle-tracking model, in which each simulated particle represented a cohort of sea lice larvae. Each of these particles was coupled to a biological model that dictated the maturation and survivorship of the particle based on the salinity and temperature it encountered (Stucchi et al. 2011; Cantrell et al. 2018).

The details of the equations governing the biology of the sea lice larvae can be found in (Cantrell et al. 2018). In short, particles where released as pre-infectious nauplii, which matured into infectious copepods at a rate that was temperature dependent. The relationship between temperature and maturity was set as a Bělehrádek equation, with lower temperatures resulting in slower maturation rates Additionally, salinity impacts nauplii particle survival, with salinity below 30 psu resulting in decreased survival. Survival decreased at a constant rate once particles matured into copepods due to a lack of agreement in the literature as to the precise relationship between salinity and survival for sea lice copepods.

The offline particle-tracking model simulated the release of 50 particles from each farm $(n=20)$ every hour, for the duration of the simulation. Each release of particles is referred to as a pulse. The first day of pulses began on March $11^{\text {th }}, 2009$, and the last day of pulses was on July $20^{\text {th }}$, resulting in 129 total days, and 3096 pulses. The location and status of each particle was tracked for 11 days, in order to simulate the hypothetical lifespan of a sea lice copepod in the temperature conditions typical of the BA, with locations recorded at 20-minute time steps. 


\section{Connectivity calculations}

Details of the methods used to calculate connectivity using the particle tracking releases can be found in Cantrell et al. (2018). In brief, the infestation pressure (IP) each farm exerted on every other farm was estimated as follows: a cohort of sea lice was defined as 24 hours of particle pulses, and each of these groups was labelled as a "cohort release day" (CRD). The offline particletracking model recorded location, maturation, and survivorship of all particles in each CRD every 24 hours for 11 days. These 11 "snapshots" taken for 24 hours worth of pulses were then combined into a single shape file. Thus, each CRD represents the entire life of a cohort of particles released from all farms on one particular day of the simulation (Fig. 2 in Cantrell et al. 2018).

Each CRD was then separated by emitting farm (i.e. all particles released from a single farm) and used as the input for kernel density estimations (KDE), which were then saved as raster files (129 CRDs x 20 farms $=2,580$ raster files). From each raster file, the density of particles at the grid section in which each farm was located was extracted. This density represents the IP that a given

farm exerted on all other farms as well as on itself (self infestation), measured in particles $\mathrm{km}^{-2}$. These densities were stored in connectivity matrices, which were then summed and averaged (mean) for all 20 farms per CRD. These matrices could then be used to estimate a mean connectivity value for all connections in the entire network of farms for each CRD in the simulation. Using this methodological approach, Cantrell et al. (2018) identified four distinct subnetworks of farms (Fig. 1). 
Farm connectivity with different biological drivers (i.e. maturation and survivorship)

The mean connectivity score for every CRD was calculated for the entire network and for the four sub-networks. Additionally, each sub-network's mean connectivity was calculated under four different scenarios to determine the relative contribution of the maturation and survivorship coefficients of the biological model by investigating the differences between the following four simulation scenarios:

I. Physical simulation only, which excludes all parts of the biological model (particles are passive);

II. Physical simulation plus survivorship simulation, which excludes the impacts of temperature (includes only the impact of salinity on the survivorship in the biological model and the physical simulation);

III. Physical simulation plus maturation simulation, which excludes the impacts of salinity on the biological model (includes only the impacts of temperature on the maturation in the biological model, and the physical simulation);

IV. Physical simulation plus maturation and survivorship simulation, (includes the impact from both temperature and salinity on the maturation and survivorship, respectively, and the physical simulation).

As an indicator of factors explaining global connectivity for each sub-network, the area under the curve (AUC) of the mean connectivity plots for all CRDs was calculated for the four simulations of the four sub-networks (Figures not shown, values of AUC are given in the supplementary materials) using the MESS package in R studio, which uses spline integration (Claus Thorn Ekstrom 2017). The percent reduction in AUC compared to the physical model only simulation (i.e. particle tracking simulation without the biological model), was then calculated for each simulation and sub-network (Table 1). 
Generalized Additive Model to determine drivers of connectivity strength

A GAM approach was used to identify environmental and biological factors influencing the emergent pattern seen in temporal variability in network connectivity. This modelling approach was chosen because GAM allows the relaxing of the assumption of linearity between the predictor and response variables by combining spline functions into a smoother line that best describes the relationship. GAMs also do not need to determine the functional form of the relationship beforehand (Guisan et al. 2016). Each sub-network was modelled separately in order to account for the hierarchy in the data and facilitate interpretation of the results, rather than using a generalized additive mixed model (GAMM). The response variable was the mean connectivity per CRD for the sub-network. Four independent predictors were assessed:

I. River discharge in $\mathrm{m}^{3} \mathrm{~s}^{-1}$, as measured at river mouths in the BA (discharge contributions from eight rivers, with each river assigned to the closest sub-network);

II. Daily solar heat flux value in watts $\mathrm{m}^{-2}$ (identical across the model domain);

III. Either maximum daily or mean daily "along channel" wind velocity in $\mathrm{ms}^{-1}$, extracted from a location near each sub-network, which ever was more significant (coordinates in the supplementary materials). The sign of the wind gust (i.e. positive or negative) indicated wind direction (i.e. "up channel”, or seaward). The cross channel wind direction was not used, as it is unlikely to contribute significantly to the movement of particles up or down the channels. The maximum daily wind velocity was the more significant predictor for subnetworks 1,2 , and 4 . Mean wind velocity was the more significant predictor for subnetwork 3;

IV. Daily tidal range (maximum minus minimum sea surface height) in $\mathrm{m}$, from the Port Hardy tidal gauge $\left(50.6838^{\circ} \mathrm{N}, 127.3772^{\circ} \mathrm{W}\right)$, identical across the model domain. Note that sea 
surface height values have the potential to be impacted by other factors, such as winds. However, in this case, there was no collinearity observed between tidal height and other predictors, and tides are the main drivers of sea surface height in this area.

Given that each CRD includes 11 days worth of connectivity information, each predictor was calculated as a rolling 11-day average to mirror the CRD structure. This resulted in a time series of 129 time points, each an 11-day rolling average.

Each independent predictor was used as an individual predictor first. Any sub-networks that had more than one predictor with a p-value $<0.15$ were then modelled with all possible combinations of these predictors, including interactions. The top model was selected using AIC model selection techniques to maximise explanatory power with model parsimony (Burnham and Anderson 2002).

The time series of all predictors (river discharge, heat flux forcing, winds, and tides) were checked for autocorrelation using an autocorrelation function ("acf" command in the mgcv package in R) (Wood 2006), (R core team, 2018). All predictors showed substantial autocorrelation, so an autoregressive term was included in all models. The value of rho for each model was computed by extracting the lag 1 value from the autocorrelation function residuals of each model. Rho values ranged from 0.77-0.9. The fast restricted maximum likelihood method was used for model building and comparisons (command, method ="fREML" in the bam() command of the mgcv package in R) (Wood 2006). The number of knots for all models was set using generalized cross validation in the mgcv package in $\mathrm{R}$ (Wood 2006). Heat flux and river discharge demonstrated collinearity (possibly because hotter days could result in more run-off from snow melt, though potentially with a time lag), so were not considered together in one model. GAM smoothers were 
added to each plot of predictor vs. sub-network in order to more easily visualize the relationship between the two.

\section{Sensitivity Analysis}

A sensitivity analysis of the biological parameters (maturation and survivorship) was conducted for sub-network 2 (farms 6-7, and 16-18), because this sub-network most closely reflected the overall trend seen when all farms were grouped together (i.e. sub-network 2 also showed evidence of the four peaks seen in the overall connectivity plot, at the beginning of the simulation and at CRDs 59, 93, and 123, as seen in Fig. 2D). The sensitivity tests consisted of four simulations, where the values for maturation or survivorship for each particle for each time step was adjusted in the following ways: maturation decreased to $50 \%$; maturation increased to $150 \%$; survivorship decreased to $50 \%$; survivorship increased to $150 \%$.

The total IP that the farms in sub-network 2 exerted on all of the other farms was calculated for every CRD in the simulation. Self-infestation was excluded to highlight the strength of connectivity among farms (i.e. the likelihood of parasite transmission between farms), rather than emphasizing CRDs that had high connectivity within farms. This IP was plotted for every CRD, and the results of the four simulations were compared with the simulation based on the full biological model (with both survivorship/maturation at their default levels).

\section{Results}

Overall farm connectivity strength under different scenarios

The strength of the network connectivity for the physical model simulation is the highest of the four simulations (Fig. 2a). The mean connectivity across the entire network for the physical model 
simulation (Fig. 2a) also has less temporal variability than the other simulations. The IP experienced per CRD ranges roughly between 7.8 and 10 particles $\mathrm{km}^{-2}$, representing $22 \%$ variation.

The survivorship only simulation (Fig. 2b) had lower connectivity strength than the maturation only simulation (Fig. 2c). The IP ranged between roughly 0.6 and 2.4 particles $\mathrm{km}^{-2}$, representing $75 \%$ variation. The survivorship only simulation also had a peak at the start of the simulation, followed by a gradual decrease for the remainder of the simulation. There are no peaks at CRDs 59, 93 and 123, as seen in the survivorship/maturation simulation (Fig. 2b) or the maturation simulation (Fig. 2c).

Not surprisingly, both simulations with only a portion of the biological model (the maturation only and survivorship only simulations) showed connectivity strength and variability intermediate between the physical model and full biological model (survivorship/maturation) simulations. The IP in the maturation only simulation (Fig. 2c) ranged from roughly 3.5 to 7.5 particles $\mathrm{km}^{-2}$, representing $53 \%$ variation. This simulation has a similar pattern to the full biological model simulation (Fig. 2d) in that there is a peak in connectivity in the beginning of the simulation that decreases over the first $20 \mathrm{CRDs}$, though the peak is smaller than that seen in the maturationsurvivorship simulations. The peaks in connectivity at CRD 59, 93, and 123 also exist in the maturation simulation.

The survivorship-maturation simulation has the lowest overall connectivity (Fig. 2d), decreased by an order of magnitude over the purely physical simulation. The infestation pressure ranges roughly between 0.01 and 0.29 particles $\mathrm{km}^{-2}$, representing $97 \%$ variation. There is a distinct pattern that 
emerges, with the initial CRDs having a much higher overall connectivity than the rest of the simulation, and then sharply decreasing over the first 20 CRDs. There are also distinct peaks around CRDs 59 and 93, and a smaller peak around CRD 123. Possible reasons for this pattern are explained in the discussion.

\section{Sub-network connectivity differences}

The drivers of the temporal variability were also explored by sub-network for the simulation that included all aspects of the biological model (the survivorship/maturation simulation). Sub-network 1 (Fig. 3a) and sub-network 4 (Fig 3d) do not have peaks at CRD 123. Additionally, the initial peak in connectivity strength is lower than in sub-networks 2 or 3. Sub-network 2 (Fig. 3b) has the same steep starting peak, as well as peaks at CRD 59, 93, and 123 that are present in Fig. $2 \mathrm{~d}$. Sub-network 3 (Fig. 3c) has only a small increase at CRD 59. Sub-network 4 (Fig. 3d) has a low overall connectivity. However, even with the low connectivity, there is still a slightly higher connectivity at the start of the simulation, as well as at CRD 93.

The maturation only simulation resulted in a 40-68\% reduction in the AUC depending on network. For the survivorship only simulation the reduction in AUC was greater than $80 \%$ for all subnetworks. When the full biological model (survivorship and maturation) was used the value of the AUC was reduced by over $99 \%$.

\section{Salinity and temperature as drivers of the biological model}

The mean salinity that each cohort encountered over the 11-day tracking period suggests that there was an overall decrease in salinity throughout the entire simulation period (Fig. 5a) coinciding with the river discharge increase (Fig. 5a, supplementary materials, and 7a- though the increase is 
not monotonic here). The temperature drops during the first 20 or so CRDs, but with a subsequent upswing peaking at CRD 59. There is a second increasing trend with a peak at CRD 93, with the temperature remaining higher until the end of the simulation, and a small peak again at CRD 123 (Fig. 4b). The water temperature increased on these days due to increases in the heat flux (Fig. 5b).

Within each individual cohort, there is a hooked shape seen in both Figs 5a and 5b. Cohorts start out at a lower salinity (Fig. 5a) and higher temperature (Fig. 5b). Salinity increases and temperature decreases over the CRD life, and then levels out slightly lower than the maximum salinity, and slightly higher than the minimum temperature. This shape is due to the vertical velocity components. Because the particles have not been assigned either a swimming ability to combat these downward velocities or a density that would stop descent when neutral buoyancy was attained, they moved passively with the downward (on average) vertical currents from the near-surface depths where they were released (until reaching the maximum depth constraint of $5 \mathrm{~m})$.

Additionally, Figs. 5a and 5b have a secondary axis, showing the instantaneous survivorship and maturation for each day of the simulation with that daily temperature and salinity input into the equations governing maturation and survivorship. The secondary axis shows the close relationship between the temperature and salinity experienced by particles and the instantaneous maturation and survivorship of the particles, with each increasing or decreasing together. The threshold in the survivorship equation is apparent in approximately the first 45 CRDs in Fig 5a, where survivorship is a constant when salinity is above 30 . 


\section{Drivers of connectivity strength}

The independent predictors included in the GAM model were the 11-day rolling averages of the daily values of river discharge, total heat flux forcing, wind, and tidal range (Fig. 4). The same plots for the river discharge and winds, but showing individual river discharge and weather station wind gusts, respectively, are in the supplementary materials.

The relationship between all predictors and the connectivity for each sub-network has been graphed with smoothed plots in Fig. 6. Thus, the impact of river discharge on connectivity is roughly a nonlinear, negative relationship. When the river discharge increases, connectivity decreases as water with lower salinity floods the system. Thus, river discharge is a proxy for salinity (and thus lowers survivorship of sea lice particles). Sub-networks 1-3 were dominated by the river discharge (Fig. 6a-d), with between 56-74\% deviance explained by river discharge alone.

Total heat flux forcing (Fig. 6e-h) has the opposite, also nonlinear relationship, with increasing connectivity as temperature increases. Heat flux was significant for all sub-networks except 3.

Wind has a direction associated with the sign of the predictor, with negative indicating seaward, and positive indicating "up channel" wind direction. Sub-networks 2 and 4 were significantly predicted by wind, with the negative wind direction (seaward) having higher connectivity results for both. Wind explained $42.9 \%$ deviance for sub-network 2 (Fig. 6j) and $13.6 \%$ of the deviance for sub-network 4 (Fig. 6k). Despite this rather low deviance for sub-network 4, wind has the largest explanatory power as a univariate predictor for this sub-network; the connectivity was not well explained by any of the four predictors examined. 
Tidal range was only significant for sub-network 2 (Fig. 6m-g). The relationship is roughly linear and negative, so as tidal range increases, connectivity decreases.

For all sub-networks, all predictors with p-values $<0.15$ were combined, as well as their interactions were tested in further GAMs (Table 3). The model for sub-network 1 did not improve from adding additional predictors to the river discharge predictor alone, or have any significant interactions. The top model based on AIC selection techniques from sub-network 2 was also from river discharge as a predictor alone. However, the interaction for wind and tide was significant $(\mathrm{p}=0.002)$, and the model with river discharge and the interaction between wind and tide accounted for $82.3 \%$ of the deviance (despite having a higher AIC score). Sub-network 3 had only one predictor (river discharge) as statistically significant, so no further predictors were considered. The top AIC selected model for sub-network 4 included both heat-flux and wind, which resulted in a still poor percent deviance explained, of $32.4 \%$.

\section{9 as a representative year}

To determine how representative the simulation period was (March-July, 2009), the main driver of connectivity strength (river discharge) was plotted against a historical dataset of river discharge. This historical dataset has 41 years of data on river discharge from the Kliniklani River (Fig. 7). Kliniklani discharge data began to be collected in 1968, and continues currently, however we only examined data up until the simulations time period (2009). The Kliniklani has the largest discharge in the BA, and is thus the most important in terms of impact on local circulation (Foreman et al. 2015). The daily means for 2009 had 26 days during the simulation period that were outside of the standard deviation for the 41-year daily means. These occurred around simulation day 50, 100, and after day 140 (Fig. 7a). However, despite some daily variation, the daily cumulative average for 
2009 was within the standard deviations of the 41-year average for the entire simulation period (Fig. 7b). Thus, the two plots show that while there are a few days with variability outside of the standard deviation of the 41 year mean, over all, 2009 remains well within what is "typical" for the BA.

\section{Sensitivity Analysis}

Sensitivity analysis revealed that changing the maturation and survivorship parameters changed the magnitude of connectivity, but not the pattern in the timing of temporal spikes (i.e. there are still peaks on the same CRDs). The AUC calculations quantify the change in magnitude compared to the full biological model (survivorship/ maturation) simulation (Table 2). The percent change ranges from $38 \%$ to $414 \%$, and changes in the maturation impact the AUC more than changes in the survival. Fig. 8 is the mean connectivity for each CRD for the sensitivity analysis simulations.

\section{Discussion}

This study presents the output of a coupled bio-physical model of sea lice dispersal from salmon farms in the BA. The results provide a framework for how to analyse output from such models to quantify which processes affect the dispersion and viability of water-borne pathogens. The connectivity of the farms displayed high temporal variability, an emergent pattern that results from the many interacting aspects of both the biological and the physical model. GAM was used to elucidate the main drivers of the population level behaviour in the simulation. These outputs suggested that temporal patterns were largely dictated by the influence of the spring freshet, which caused declines in the salinity and temperature of surface waters, and thus modulated the number of particles that survived and matured into infectious copepodids. Thus, the temporal variability was largely the result of the biological model of sea lice survivorship and maturation associated 
with each particle in the simulation being impacted by the physical model conditions. The spring freshet decreases survivorship and slows maturation for larvae located in the upper layers of water. However, temporary spikes in connectivity can occur when temporary heat flux forcing spikes lead to temperature increases into the ideal range for sea lice larval maturation (100\% hatching and development success was found to occur between $15-20^{\circ} \mathrm{C}$ by Samsing et al. 2016). Additionally, spikes occurred when winds were blowing seaward, which allows particles to come into contact with other farms, rather than being blown towards the top of the fjordic channels where it cannot encounter another farm.

\section{Temporal variability in pathogen viability}

The rapid decrease seen in the first 20 CRDs of the survivorship/maturation simulation appears to some extent in both the survivorship simulation, and the maturation simulation. Neither part of the biological model clearly explains the entirety of the peak seen in the first 20 CRDs, suggesting the impacts of the maturation and survivorship aspects of the simulation are cumulative.

An important part of the circulation of the BA is the spring freshet, when the snow in the surrounding mountains melts. This results in fresh, cold water entering the BA through river discharge at an average daily discharge rate upwards of $700 \mathrm{~m}^{3} \mathrm{~s}^{-1}$ by July. This was explicitly modelled in the underlying circulation model, and seems to be the single largest driving factor of the changes in salinity that impact survivorship in the biological model. Salinity gradually decreases as the simulation progresses (Fig. 5), with certain cohorts (i.e. around cohorts 105 and 135) experiencing even larger decreases in salinity. The decrease in salinity corresponds to a decrease in survivorship. Additionally, temperature also drops during this time, also due to the spring freshet event, as discharged water is colder than the ocean water. This results in fewer 
particles reaching maturation. Thus the first steep drop in connectivity seen in the full biological model (the survivorship-maturation simulation) is due to the cumulative effects from a decrease in salinity and temperature, driven by the spring freshet ramping up. This results in fewer infectious sea lice copepods being present in the model domain, leading to a decrease in the strength of connectivity across the entire network. The high impact of the spring freshet was confirmed by GAM modelling, where between 56-76\% of the deviance was explained by river discharge alone, for sub-networks 1-3. The fact river discharge was so much more important as a predictor for connectivity than heat flux forcing also confirms the importance of survivorship on connectivity, which is driven by salinity.

The spring freshet might be acting as a "natural control" in the BA, slowing sea lice larval development and thus helping to keep sea lice loads low, which has also been suggested elsewhere (Brooks 2005). Thus with the current climate warming, a reduction in snowpack and glaciers is expected to reduce this "natural control" effect (Kang et al. 2016; Najafi et al. 2017). Additionally, warmer waters would result in shorter maturation times, and thus a higher density of infectious sea lice larvae in the water column. This suggests sea lice infection pressure will increase with time if climate change continues unabated (Bateman et al. 2016).

Despite the importance of the freshet event and salinity on overall farm-to-farm connectivity in sea lice infection, we still find evidence for the importance of temperature on the temporal variability of these connectivity patterns. In the BA, temperature can be regulated by the spring freshet (as described above) and the heat flux forcing of the system to modulate surface water temperature. We observe a decrease in temperature seen in the first 20 CRDs (due to the river discharge) followed by a gradual increase in temperature and spikes around CRDs 59, 93, and 123 (due to 
temporary increases in the heat flux forcing). These spikes appear in the simulation with both the survivorship/maturation, and also appear in the maturation simulation, but not the survivorship simulation. This demonstrates that maturation, which is dictated by temperature (which is in turn, impacted by both the heat flux and the river discharge), is the main driver of the spikes in the network strength on those particular CRDs. However, the spikes at CRDs 59, 93, and 123, do not reach the connectivity strength seen at the start of the simulation (Fig. 2b). Thus, the heat flux forcing alone was not enough to overcome the impacts of the river discharge on survivorship, probably because of the countering effect of cold river discharge from snow and glacial run-off. Additionally, the relatively colder, fresher water tends to stay mostly in a less dense upper layer in the water column during a freshet event (particularly in fjordic areas), where sea lice are generally located (Oppedal et al. 2017).

Temporal variability in disease connectivity has been observed in multiyear and annual simulations from other regions. Samsing et al. (2017) ran bio-physical simulations of the Norwegian west coast for six years and found strong seasonality in the farm-to-farm connectivity of sea lice infection, with consistency of seasons across years; although connectivity drivers across seasons were not discussed. Adams et al. (2016) simulated the Scottish west coast for one year, and found farm-to-farm sea lice infection connectivity varied over time by a factor of two; similarly, particular drivers of why this variation exists were not in the scope of the paper. This suggests that high temporal variability in network connectivity strength in pathogen dispersal may be the rule, rather than an exception, and thus any connectivity or larval dispersal simulations could benefit from analyzing temporal variability. Additionally, any management recommendations made from simulations should use a precautionary management approach, with the "worst case scenario" in mind (i.e. conditions for when the connectivity strength is the highest), 
as even temporally short "pulses" of high connectivity strength can result in outbreak scenarios (Velentgas et al. 2013).

\section{Simulation time period}

Our model simulates circulation conditions from March-July 2009. The representativeness of a "typical" year for the BA is important for applying results to other years. Cumulative discharge for 2009 was within the standard deviation of the 41-year mean for the entire simulation period. However, $17 \%$ of the days in the simulation period had daily discharge values outside of the standard deviations of the 41-year daily mean, generally due to unusually large storm events, of which there were none during our simulation period. River discharge was the most important factor impacting connectivity across every connected sub-network of farms. (ie sub-networks 1-3). Therefore, the circulation conditions of 2009 are likely relatively "typical" for the region, which increases confidence in applying model results to other "typical" years. However, caution should be used when applying results to non-typical years (i.e. years with unusually small snow pack in the mountains and thus a smaller freshet event, or unusually warm years, or years when the freshet timing may be off). These scenarios may be particularly important in the context of climate change.

\section{Spatial drivers of pathogen dispersion}

The fact that the four sub-networks resulted in different variables for creating the top selected GAM models demonstrates that environmental drivers of connectivity can vary, even on relatively small spatial scales. It is perhaps not surprising that the farms belonging to sub-network 4 were not as impacted by river discharge as the other sub-networks, given that the farms involved in this subnetwork are closer to the open ocean, and furthest away from the mouths of rivers compared to the other sub-networks. It is worth noting that though we called these farms "sub-network 4" for ease 
of discussion, they are in fact a group of independent, unconnected farms. Most of the particles released from these farms were simply flushed out to sea. Thus, it is likely the connectivity was so low for this sub-network, finding significant associations with any driver would be difficult, and the top selected model of both wind and heat-flux only explaining $32.4 \%$ of the deviance is perhaps to be expected. Likewise, the relationship of sub-networks 1-3 to river discharge is perhaps not surprising, given the much closer proximity of these sub-networks to large river mouths.

The GAM models indicate wind to be an important driver in sub-networks 2 and 4. Sub-network 2 is in a more closed, protected area of the BA. The negative wind direction (seaward) has a strongly positive association with connectivity strength. This could be because wind in the seaward direction (i.e. a south—westerly wind for sub-networks 1 and 2) would create surface currents that would carry particles from these sub-networks of farms into contact with other farms. For subnetwork 2, a southwesterly wind would push the particles towards each other, to circulate in the area, rather than being flushed out and away from the farms. There is a less strong, but still significant relationship between wind and connectivity strength in sub-network 4 . For this subnetwork, a north-westerly wind would push particles from farms 19-20 towards farms 8, 9 and 1214 , thus increasing connectivity amongst this low connected sub-network, rather than just being flushed out of the BA before encountering other farms. Sub-network 1 was not significantly driven by wind; however, this variable was retained in the top selected model. Furthermore, this subnetwork shares the same trend in wind direction (i.e. seaward resulting in the highest connectivity) as observed for sub-networks 1 and 4 . Only sub-network 3 did not share this trend and seemed to be poorly explained by wind. Though this could be due, in part, to the fact this sub-network had 
such a large impact from the river discharge, it essentially "drowned" out any signal from other drivers.

Tidal range was not detected by the GAM modeling approach to be an important driver in farm-tofarm connectivity of sea lice infection. However, this could be due in part to the way the particles were grouped in our analysis. Twenty-four hours of particle pulses where grouped together as one "cohort", which could alias the influence of tidal cycles. However, the 24-hour grouping of cohorts would not mask tidal fluctuations longer than 24 hours in duration (e.g., spring and neap tides), or seasonal variations in tides, such as the higher tides seen near the summer solstice. This seasonal variation is more important from an epidemiological perspective, as individual tidal cycle impacts would be for short period (on the scale of hours) and would essentially repeat daily. Thus, the variation in IP strength caused from daily tidal cycles would be similar from day to day. Additionally, the AUC calculations (Table 2) suggest that adding the survivorship of the particles to the simulation results in a larger reduction in connectivity of the sub-networks. Survivorship reflects mainly the impact of the freshet. The reduction in AUC from maturation (reflecting the impact of both heat flux and the spring freshet) is both smaller and more variable across subnetworks. This variation is likely a reflection of differences in time particles emitted from each sub-network have around other farms before being flushed out of the vicinity. Sub-network 4 has the largest impact from maturity, because it had very few particles connect with other farms. Thus, adding the maturation restriction (i.e. the particles do not "count" in the first few days of their lives as they are not yet viable) has a larger impact on this sub-network's connectivity to the other farms than the other sub-networks. Sub-network 2 has the lowest impact from maturity, as the time those particles spend around other farms in the BA is quite high, thus adding maturity to the simulation had a smaller impact. 


\section{Impacts of changes in the biological model on connectivity strength}

The sensitivity analysis revealed that changing the biological model outcomes by increasing or decreasing the survivorship and maturation values assigned to each particle resulted in changes in the strength of connectivity, but did not change the overall pattern observed. In other words, the particles $\mathrm{km}^{-2}$ might increase with increasing maturation values, but the peaks seen at the beginning of the simulation, as well as at CRDs 59, 93, and 123 remained. This could be important if the objective is to estimate exact infestation pressures, to keep exposure below a certain infectious dose. However, in the case of sea lice, the infectious dose necessary to result in a

sea lice infestation is not known. Therefore, translating the absolute number of particles $\mathrm{km}^{-2}$ into absolute risk values is not yet possible (Frenzl 2014). It is, however, possible to consider relative risk and recommend spatial management solutions that may reduce the likelihood of outbreaks. These do not change whether the connectivity strength is small or large or orders of magnitude different. Therefore, in the case of this particular study, the sensitivity analysis revealed that the parameters are robust when the goal is to identify connectivity patterns.

\section{Applied results for the salmon industry}

Outputs from bio-physical simulations for disease management in aquaculture (not only for sea lice, but for any larval and/or pathogen connectivity study) need to be validated by field data before being implemented, as excluding key parts of larval biology can change the spatial connectivity pattern and/or temporal variability tied to the life history of the larvae. Validation of parasitic larvae dispersal models is difficult and expensive. Some attempts at validation with field data include plankton tows in areas with higher risk of infestation pressure, as well as sentinel cages (Pert et al. 2014). However, because sea lice larvae tend to be quite low in concentration in 
the water column, typically fewer than five sea lice larvae are found in each standard tow. The low sample size makes this method a less than ideal validation method. Additionally, it is difficult to account for the impact of wild salmon on disease transmission, as wild salmon routes are not fully known and sea lice connectivity simulations thus far do not explicitly model wild salmon populations. Nevertheless, validation of this model must be undertaken before management suggestions are implemented, and thus is the focus of ongoing research.

At this stage, the model output can allow for some practical recommendations for the salmon farming industry in the BA. Model output suggests that outbreak scenarios are more likely to result when river discharge is low. Years with less snow pack in the surrounding mountains could contribute to more difficult sea lice management. Managers can also anticipate outbreaks during warmer time periods, and during periods with seaward winds for each sub-network, which will keep particles in the BA for longer, and thus result in a higher infestation pressure. This result is a particular concern as the temperature of the BA coastal waters rise with global warming (Wolff et al. 2017).

Additionally, the model could be used to simulate hypothetical scenarios to explore the impact of management practices on sea lice transmission. For example, the effect of coordinated treatment could be explored by analyzing connectivity after the removal of sea lice from one/several farms at a given time

Any farms kept in current locations or future farms placed near current farm locations should consider using these sub-networks as treatment areas for sea lice management, as treating only one farm will likely result in re-infection. Additionally, future farm locations placed near the current 
sub-network 4 could result in farms less connected via shared pathogens. Care should be taken to not place farms near the current farm 11, which acts as a pathway to connect sub-networks 1 and 3 (see Cantrell et al. 2018). Model results suggest that farms located closer to the open ocean are less likely to infect one-another; however, the role of farms in these locations to infect wild salmon populations is not known and requires further investigation.

\section{The relevance of sea lice biology on connectivity}

Our simulations suggested that connectivity output from coupled bio-physical models is potentially highly dependent on the biological model of the particle whose dispersal is being simulated (in our case, the sea lice copepod). However, as recently highlighted in the review paper by Brooker et al. (2018), there is no final consensus around the parameters or equations governing sea lice biology. Thus, marine epidemiology, sea lice modelling, and spatial ecology scientific communities would benefit from a consensus being reached on the impact of salinity and temperature on the life history of the sea lice larvae.

There are conflicting reports on how salinity and temperature impact sea lice. For example, Groner et al. (2015) used existing literature on salinity impacts on different life stages of sea lice to fit salinity dependent logistic-mortality curves, and found that salinity has a non-linear effect on sea louse survival, with most effects at less than $20 \mathrm{psu}$; a value substantially lower than the threshold in our study, which was 30 psu. However, other studies found impacts of salinity on mortality began at much higher salinity. For example, Bricknell et al. (2006) found that at 29 ppt survival was severely reduced, and larvae had a reduced ability to sense or respond to the presence of a host; a behaviour that our simulation did not explicitly model. Johnson and Albright (1991) found 
reduced activity and survival below $25 \mathrm{ppt}$ (Note that these studies measured salinity in different units, ppt vs psu, but for practical purposes they are nearly equivalent).

In terms of impact of temperature on development time from nauplius to infectious copepod, Gravil (1996), Boxaspen and Naess (2000), and Samsing et al. (2016) found different development times based on nauplius stage, as well as impacts on egg development time. None of these individual stages were explicitly modelled in our simulation, where particles were considered only pre-infectious or infectious (i.e. copepodids). While lacking agreement on specific times for each development stage, all studies on the impacts of temperature on maturation found a substantial positive relationship, with warmer waters decreasing development time. This relationship suggests that future scenarios of warming oceans could render control of sea lice more difficult (Groner et al. 2014; Gallana et al. 2016; Cunningham et al. 2017; Algeo et al. 2019).

\section{Model limitations}

Our simulation did not explicitly model several aspects of sea lice larval life history. For example, the impacts of salinity and temperature on egg hatching rates and success were not modelled. Additionally, diel vertical migrations have been shown to impact horizontal dispersion of sea lice, reducing dispersal lengths (Johnsen et al. 2016). Particles in our simulation were not given diel migration behaviours, thus our simulation may over estimate dispersion lengths, which could result in the sub-networks being identified to include farms that should not be included.

Settlement of infectious particles on hosts was also not explicitly simulated, though contact time of infectious copepods and competition for space on hosts is known to be important for attachment rates (Frenzl 2014). However, for agent based models to successfully capture emergent behaviours, 
it is not necessary (nor feasible) to model every single detail of a system (Grimm et al. 2005). Though we did not explicitly model impacts on host seeking behaviour and settlement, we did model the impact of salinity on survivorship, with salinity below 31 psu adversely impacting survival. This was one of the higher salinity thresholds in the literature. This most likely captures at least some aspects of survival and settlement impacts, and would again mean dispersal lengths are over estimated in our simulation. Accordingly, both of these limitations represent a "worst case scenario" in terms of connectivity, which is compatible with the proposed precautionary approach to sea lice management. We also were not able to include wild salmon in the simulation, which could act as vectors for sea lice transmission in addition to the hydro-dynamic connectivity explored in this paper.

\section{Conclusions}

The outcomes of this coupled bio-physical modelling exercise emphasize the importance of physical exchange in the absolute magnitude of connectivity. As indicated, the addition of biological parameters greatly attenuates connectivity. For pathogens where biological aspects are poorly understood (viruses), physical connectivity alone would provide an uncertain representation of infection pressure. In addition, uncertainty in the physical model or its forcing inputs (e.g. wind) would introduce large errors in the modelling framework if biological components were subsequently added as layers.

In terms of sea lice management specifically, the temporal variability in the network strength is important from an epidemiological perspective, as even small peaks in infectious dosage can result in higher incidents of disease (Frenzl 2014). Therefore, a precautionary approach to management should be used i.e. plan for the times when higher temperature and salinity would result in more 
infectious copepods in the water. Similarly, modelling assumptions should aim to capture "worse case scenarios", i.e. maximizing connectivity. The spring freshet event was the single most important driver of sea lice connectivity in the Broughton Archipelago region, and played a role in attenuating the strength of the connectivity between farms. Epidemiologically relevant spatial management holds promise towards improving the sustainability of the aquaculture industry, by refining the efficacy and economics of infectious disease treatments, improving farmed fish welfare, and minimizing pathogen spill over to wild fish stocks.

\section{Acknowledgements}

This study was funded by an NSERC Collaborative Research and Development Grant to JG and RF, and by the Industrial Research Chair in Sustainable Aquaculture held by JG at Dalhousie University. 


\section{References}

Aaen, S.M., Helgesen, K.O., Bakke, M.J., Kaur, K., and Horsberg, T.E. 2015. Drug resistance in sea lice: A threat to salmonid aquaculture. Trends Parasitol. 31(2): 72-81. Elsevier Ltd. doi:10.1016/j.pt.2014.12.006.

Adams, T., Aleynik, D., and Black, K. 2016. Temporal variability in sea lice population connectivity and implications for regional management protocols. Aquac. Environ. Interact. 8: 585-596.

doi:10.3354/aei00203.

Adams, T., Black, K., MacIntyre, C., MacIntyre, I., and Dean, R. 2012. Connectivity modelling and network analysis of sea lice infection in Loch Fyne, west coast of Scotland. Aquac. Environ. Interact. 3(1): 51-63. doi:10.3354/aei00052.

Adams, T.P., Proud, R., and Black, K.D. 2015. Connected networks of sea lice populations: Dynamics and implications for control. Aquac. Environ. Interact. 6(3): 273-284. doi:10.3354/aei00133.

Aldrin, M., Storvik, B., Kristoffersen, A.B., and Jansen, P.A. 2013. Space-Time Modelling of the Spread of Salmon Lice between and within Norwegian Marine Salmon Farms. PLoS One 8(5): 1-10. doi:10.1371/journal.pone.0064039.

Algeo, T., P., Chipman, R., B., Slate, D., Freier, J., E., and DeLiberto, T., J. 2019. Predicted Wildlife Disease-Related Climate Change Impacts of Specific Concern to USDA APHIS Wildlife Services. Proc. Vertebr. Pest Conf. 26(2001): 310-315. doi:10.5070/v426110483.

Arnold, W.S., Meyers, S.D., Geiger, S.P., Luther, M.E., Narváez, D., Frischer, M.E., and Hofmann, E. 2017. Applying a Coupled Biophysical Model to Predict Larval Dispersal and Source/Sink Relationships in a Depleted Metapopulation of the Eastern Oyster Crassostrea virginica. J. Shellfish Res. 36(1): 101-118. National Shellfisheries Association. doi:10.2983/036.036.0112.

Asplin, L., Johnsen, I.A., Sandvik, A.D., Albretsen, J., Sundfjord, V., Aure, J., and Boxaspen, K.K. 2014. Dispersion of salmon lice in the Hardangerfjord. Mar. Biol. Res. 10(3): 216-225.

doi:10.1080/17451000.2013.810755.

Bateman, A.W., Peacock, S.J., Connors, B., Polk, Z., Berg, D., Krkošek, M., and Morton, A. 2016. Recent failure to control sea louse outbreaks on salmon in the Broughton Archipelago, British Columbia. Can. J. Fish. Aquat. Sci. 73(8): 1164-1172. doi:10.1139/cjfas-2016-0122.

Boxaspen, K. 2006. A review of the biology and genetics of sea lice. ICES J. Mar. Sci. 63(7): 1304-1316. Oxford University Press. doi:10.1016/j.icesjms.2006.04.017.

Brauner, C.J., Sackville, M., Gallagher, Z., Tang, S., Nendick, L., and Farrell, A.P. 2012. Physiological consequences of the salmon louse (Lepeophtheirus salmonis) on juvenile pink salmon (Oncorhynchus gorbuscha): implications for wild salmon ecology and management, and for salmon aquaculture. Philos. Trans. R. Soc. B Biol. Sci. 367(1596): 1770-1779. doi:10.1098/rstb.2011.0423.

Brooker, A.J., Skern-Mauritzen, R., and Bron, J.E. 2018. Production, mortality, and infectivity of planktonic larval sea lice, Lepeophtheirus salmonis (Kroyer, 1837): Current knowledge and implications for epidemiological modelling. ICES J. Mar. Sci. 75(4): 1214-1234. doi:10.1093/icesjms/fsy015.

Brooks, K.M. 2005. The effects of water temperature, salinity, and currents on the survival and distribution of the infective copepodid stage of sea lice (Lepeophtheirus salmonis) originating on atlantic salmon farms 
in the Broughton Archipelago of British Columbia, Canada. Rev. Fish. Sci. 13(3): 177-204. doi:10.1080/10641260500207109.

Burnham, K.P., and Anderson, D.R. 2004. Multimodel inference: Understanding AIC and BIC in model selection. 261 Sociological Methods Research. doi:10.1177/0049124104268644.

Cantrell, D.L., Rees, E.E., Vanderstichel, R., Grant, J., Filgueira, R., and Revie, C.W. 2018. The Use of Kernel Density Estimation With a Bio-Physical Model Provides a Method to Quantify Connectivity Among Salmon Farms: Spatial Planning and Management With Epidemiological Relevance. Front. Vet. Sci. 5: 269. Frontiers. doi:10.3389/fvets.2018.00269.

Chen, C., Liu, H., and Beardsley, R.C. 2003. An unstructured grid, finite-volume, three-dimensional, primitive equations ocean model: Application to coastal ocean and estuaries. J. Atmos. Ocean. Technol. 20(1): 159-186. doi:10.1175/1520-0426(2003)020<0159:AUGFVT>2.0.CO;2.

Costello, M.J. 2006, October 1. Ecology of sea lice parasitic on farmed and wild fish. Elsevier Current Trends. doi:10.1016/j.pt.2006.08.006.

Cunningham, A.A., Daszak, P., and Wood, J.L.N. 2017, July 19. One health, emerging infectious diseases and wildlife: Two decades of progress? The Royal Society. doi:10.1098/rstb.2016.0167.

Dill, L.M. 2011. Impacts of salmon farms on Fraser River sockeye salmon : results of the Dill investigation. Cohen Comm. Tech. Rep. (5C): 113p. Available from www.cohencommission.ca [accessed 8 December 2018].

Foreman, M.G.G., Chandler, P.C., Stucchi, D.J., Garver, K.A., Guo, M., Morrison, J., and Tuele, D. 2015. The ability of hydrodynamic models to inform decisions on the siting and management of aquaculture facilities in British Columbia. DFO Can. Sci. Advis. Secr. Res. Doc. 2015/005(April): vii + 49 p. doi:10.13140/RG.2.1.4973.2002.

Foreman, M.G.G., Stucchi, D.J., Zhang, Y., and Baptista, A.M. 2006. Estuarine and tidal currents in the Broughton Archipelago. Atmos. - Ocean 44(1): 47-63. doi:10.3137/ao.440104.

Foreman, M.G.G.G., Czajko, P., Stucchi, D.J., and Guo, M. 2009. A finite volume model simulation for the Broughton Archipelago, Canada. Ocean Model. 30(1): 29-47. doi:10.1016/j.ocemod.2009.05.009.

Frenzl, B. 2014. Understanding key factors associated with the infection of farmed Atlantic salmon by the salmon louse Lepeophtheirus salmonis. : 1-176. University of Stirling. Available from https://dspace.stir.ac.uk/handle/1893/22320\#.XA9Dn_ZKjOQ [accessed 10 December 2018].

Gallana, M., Ryser-Degiorgis, M.-P., Wahli, T., and Segner, H. 2016. Climate change and infectious diseases of wildlife: Altered interactions between pathogens, vectors and hosts. Curr. Zool. 59(3): 427-437. doi:10.1093/czoolo/59.3.427.

Grimm, V., Revilla, E., Berger, U., Jeltsch, F., Mooij, W.M., Railsback, S.F., Thulke, H.H., Weiner, J., Wiegand, T., and DeAngelis, D.L. 2005, November 11. Pattern-oriented modeling of agent-based complex systems: Lessons from ecology. American Association for the Advancement of Science.

doi:10.1126/science.1116681. 
Groner, M.L., Gettinby, G., Stormoen, M., Revie, C.W., and Cox, R. 2014. Modelling the impact of temperature-induced life history plasticity and mate limitation on the epidemic potential of a marine ectoparasite. PLoS One 9(2): e88465. Public Library of Science. doi:10.1371/journal.pone.0088465.

Groner, M.L., Mcewan, G.F., Rees, E.E., Gettinby, G., and Revie, C.W. 2016. Quantifying the influence of salinity and temperature on the population dynamics of a marine ectoparasite. Can. J. Fish. Aquat. Sci. 73(May): 1281-1291. doi:10.1139/cjfas-2015-0444.

Groner, M.L., Rogers, L.A., Bateman, A.W., Connors, M., Frazer, L.N., Godwin, S.C., Krkos, M., Lewis, M.A., Peacock, S.J., Rees, E.E., Revie, C.W., and Schla, U.E. 2016b. Lessons from sea louse and salmon epidemiology. Philos. Trans. R. Soc. B Biol. Sci. 371: 20150203. doi:10.1098/rstb.2015.0203.

Grøntvedt, R.N., Jansen, P.A., Horsberg, T.E., Helgesen, K., and Tarpai, A. 2014. The surveillance programme for resistance to chemotherapeutants in salmon lice (Lepeophtheirus salmonis ) in Norway 2013. Surveill. Program. Terr. Aquat. Anim. Norway. Annu. Rep. 2013.: 2-15. doi:ISSN 1894-5678.

Guisan, A., Edward, T.C., Jr, and Hastie, T. 2016. Generalized linear and generalized additive models in studies of species distributions: setting the scene. Ecol. Modell. 157(157): 89-100.

Holt, R.A., Amandi, A., Rohovec, J.S., and Fryer, J.L. 1989. Relation of Water Temperature to Bacterial Cold-Water Disease in Coho Salmon, Chinook Salmon, and Rainbow Trout. J. Aquat. Anim. Health 1(2): 94-101. Taylor \& Francis Group. doi:10.1080/1548-8667(1989)001[1t]0094[co]ROWTTB[gt]2.3.CO;2. Jacquet, S., and Bratbak, G. 2003. Effects of ultraviolet radiation on marine virus-phytoplankton interactions. FEMS Microbiol. Ecol. 44(3): 279-289. doi:10.1016/S0168-6496(03)00075-8.

Jansen, P.A., Kristoffersen, A.B., Viljugrein, H., Jimenez, D., Aldrin, M., and Stien, A. 2012. Sea lice as a density-dependent constraint to salmonid farming. Proc. R. Soc. B Biol. Sci. 279(1737): 2330-2338. The Royal Society. doi:10.1098/rspb.2012.0084.

Johnsen, I., Asplin, L., Sandvik, A., and Serra-Llinares, R. 2016. Salmon lice dispersion in a northern Norwegian fjord system and the impact of vertical movements. Aquac. Environ. Interact. 8: 99-116. doi:10.3354/aei00162.

Johnsen, I.A., Fiksen, $\ddot{i} \iota^{1 / 2 y v i n d, ~ S a n d v i k, ~ A . D ., ~ a n d ~ A s p l i n, ~ L . ~ 2014 . ~ V e r t i c a l ~ s a l m o n ~ l i c e ~ b e h a v i o u r ~ a s ~ a ~}$ response to environmental conditions and its influence on regional dispersion in a fjord system. Aquac. Environ. Interact. 5(2): 127-141. doi:10.3354/aei00098.

Jones, S.R.M., and Hargreaves, N.B. 2009. Infection threshold to estimate lepeophtheirus salmonisassociated mortality among juvenile pink salmon. Dis. Aquat. Organ. 84(2): 131-137. doi:10.3354/dao02043.

Jones, S.R.M., Prosperi-Porta, G., Kim, E., Callow, P., and Hargreaves, N.B. 2006. The occurence of Lepeophtheirus salmonis and Caligus clemensi (Copepoda:Caligidae) on three-spine stickleback Gasterosteus aculeatus in coastal British Columbia. J. Parasitol. 92(3): 473-480. doi:10.1645/GE-685R1.1.

Kang, D.H., Gao, H., Shi, X., Islam, S. ul, and Déry, S.J. 2016. Impacts of a Rapidly Declining Mountain Snowpack on Streamflow Timing in Canada's Fraser River Basin. Sci. Rep. 6(1): 19299. Nature Publishing Group. doi:10.1038/srep19299. 
Kough, A.S., Paris, C.B., Behringer, D.C., and Butler, M.J. 2015. Modelling the spread and connectivity of waterborne marine pathogens: The case of PaV1 in the Caribbean. In ICES Journal of Marine Science. Oxford University Press. pp. i139-i146. doi:10.1093/icesjms/fsu209.

Kragesteen, T., Simonsen, K., Visser, A., and Andersen, K. 2017. Identifying salmon lice transmission characteristics between Faroese salmon farms. Aquac. Environ. Interact. 10(Kabata 1979): 49-60. doi:10.3354/aei00252.

Kristoffersen, A.B., Jimenez, D., Viljugrein, H., Grøntvedt, R., Stien, A., Jansen, P.A., Grøntvedt, R., Stien, A., and Jansen, P.A. 2014. Large scale modelling of salmon lice (Lepeophtheirus salmonis) infection pressure based on lice monitoring data from Norwegian salmonid farms. Epidemics 9: 31-39. Elsevier B.V. doi:10.1016/j.epidem.2014.09.007.

Kristoffersen, A.B., Qviller, L., Helgesen, K.O., Vollset, K.W., Viljugrein, H., and Jansen, P.A. 2018. Quantitative risk assessment of salmon louse-induced mortality of seaward-to post-smolt Atlantic salmon. Epidemics 23: 19-33. doi:10.1016/j.epidem.2017.11.001.

Krkosek, M., Revie, C.W., Gargan, P.G., Skilbrei, O.T., Finstad, B., and Todd, C.D. 2013. Impact of parasites on salmon recruitment in the Northeast Atlantic Ocean. Proc. R. Soc. Biol. Sci. 280(1750): 20122359. doi:10.1098/rspb.2012.2359.

Lees, F., Baillie, M., Gettinby, G., and Revie, C.W. 2008. The efficacy of emamectin benzoate against infestations of Lepeophtheirus salmonis on Farmed Atlantic Salmon (Salmo salar L) in Scotland, 20022006. PLoS One 3(2): 2002-2006. Public Library of Science. doi:10.1371/journal.pone.0001549.

Lennon, J.T., and Jones, S.E. 2011. Microbial seed banks: the ecological and evolutionary implications of dormancy. Nat. Rev. Microbiol. 9(2): 119-130. Nature Publishing Group. doi:10.1038/nrmicro2504.

Lunneryd, S.-G., Boström, M.K., and Aspholm, P.E. 2015. Sealworm (Pseudoterranova decipiens) infection in grey seals (Halichoerus grypus), cod (Gadus morhua) and shorthorn sculpin (Myoxocephalus scorpius) in the Baltic Sea. Parasitol. Res. 114(1): 257-264. doi:10.1007/s00436-014-4187-z.

McEwan, G.F., Groner, M.L., Fast, M.D., Gettinby, G., and Revie, C.W. 2015. Using agent-based modelling to predict the role of wild refugia in the evolution of resistance of sea lice to chemotherapeutants. PLoS One 10(10). Public Library of Science.

Murray, A.G., and Gubbins, M. 2016. Spatial management measures for disease mitigation as practiced in Scottish aquaculture. Mar. Policy 70: 93-100. Elsevier. doi:10.1016/j.marpol.2016.04.052.

Murray, A.G., and Peeler, E.J. 2005. A framework for understanding the potential for emerging diseases in aquaculture. In Preventive Veterinary Medicine. Elsevier. pp. 223-235.

doi:10.1016/j.prevetmed.2004.10.012.

Mustafa, A., Speare, D.J., Daley, J., Conboy, G.A., and Burka, J.F. 2000. Enhanced susceptibility of seawater cultured rainbow trout, Oncorhynchus mykiss (Walbaum), to the microsporidian Loma salmonae during a primary infection with the sea louse, Lepeophtheirus salmonis. J. Fish Dis. 23(5): 337-341. John Wiley \& Sons, Ltd (10.1111). doi:10.1046/j.1365-2761.2000.00235.x.

Najafi, M.R., Zwiers, F., and Gillett, N. 2017. Attribution of the observed spring snowpack decline in British Columbia to anthropogenic climate change. J. Clim. 30(11): 4113-4130. doi:10.1175/JCLI-D-160189.1. 
Nekouei, O., Vanderstichel, R., Thakur, K., Arriagada, G., Patanasatienkul, T., Whittaker, P., Milligan, B., Stewardson, L., and Revie, C.W. 2018. Association between sea lice (Lepeophtheirus salmonis) infestation on Atlantic salmon farms and wild Pacific salmon in Muchalat Inlet, Canada. Sci. Rep. 8(1): 4023. doi:10.1038/s41598-018-22458-8.

North, E.W., Schlag, Z., Hood, R.R., Li, M., Zhong, L., Gross, T., and Kennedy, V.S. 2008. Vertical swimming behavior influences the dispersal of simulated oyster larvae in a coupled particle-tracking and hydrodynamic model of Chesapeake Bay. Mar. Ecol. Prog. Ser. 359: 99-115. doi:10.3354/meps07317.

Oppedal, F., Samsing, F., Dempster, T., Wright, D.W., Bui, S., and Stien, L.H. 2017. Sea lice infestation levels decrease with deeper 'snorkel' barriers in Atlantic salmon sea-cages. Pest Manag. Sci. 73(9): 19351943. John Wiley \& Sons, Ltd. doi:10.1002/ps.4560.

Patanasatienkul, T., Sanchez, J., Rees, E.E., Krkošek, M., Jones, S.R.M., and Revie, C.W. 2013. Sea lice infestations on juvenile chum and pink salmon in the Broughton Archipelago, Canada, from 2003 to 2012. Dis. Aquat. Organ. 105(2): 149-161. doi:10.3354/dao02616.

Pert, C.C., Fryer, R.J., Cook, P., Kilburn, R., McBeath, S., McBeath, A., Matejusova, I., Urquhart, K., Weir, S.J., McCarthy, U., Collins, C., Amundrud, T., and Bricknell, I.R. 2014. Using sentinel cages to estimate infestation pressure on salmonids from sea lice in Loch Shieldaig, Scotland. Aquac. Environ. Interact. 5(1): 49-59. doi:10.3354/aei00094.

R Core Team (2018). R: A language and environment for statistical computing. R Foundation for Statistical Computing, Vienna, Austria. URL https://www.R-project.org/.

Rees, E.E., St-Hilaire, S., Jones, S.R.M., Krkošek, M., DeDominicis, S., Foreman, M.G.G., Patanasatienkul, T., and Revie, C.W. 2015. Spatial patterns of sea lice infection among wild and captive salmon in western Canada. Landsc. Ecol. 30(6): 989-1004. doi:10.1007/s10980-015-0188-2.

Revie, C.W., Gettinby, G., Treasurer, J.W., and Wallace, C. 2003. Identifying epidemiological factors affecting sea lice Lepeophtheirus salmonis abundance on Scottish salmon farms using general linear models. Dis. Aquat. Organ. 57(1-2): 85-95. doi:10.3354/dao057085.

Rogers, L.A., Peacock, S.J., McKenzie, P., DeDominicis, S., Jones, S.R.M.M., Chandler, P., Foreman, M.G.G.G., Revie, C.W., and Krkošek, M. 2013. Modeling Parasite Dynamics on Farmed Salmon for Precautionary Conservation Management of Wild Salmon. PLoS One 8(4). doi:10.1371/journal.pone.0060096.

Salama, N.K.G., Dale, A.C., Ivanov, V. V, Cook, P.F., Pert, C.C., Collins, C.M., and Rabe, B. 2017. Using biological-physical modelling for informing sea lice dispersal in Loch Linnhe, Scotland. J. Fish Dis. (January): 1-19. doi:10.1111/jfd.12693.

Samsing, F., Johnsen, I., Dempster, T., Oppedal, F., and Treml, E.A. 2017. Network analysis reveals strong seasonality in the dispersal of a marine parasite and identifies areas for coordinated management. Landsc. Ecol. 32(10): 1953-1967. doi:10.1007/s10980-017-0557-0.

Samsing, F., Oppedal, F., Dalvin, S., Johnsen, I., Vågseth, T., and Dempster, T. 2016. Salmon lice ( Lepeophtheirus salmonis ) development times, body size, and reproductive outputs follow universal models of temperature dependence. Can. J. Fish. Aquat. Sci. 73(12): 1841-1851. doi:10.1139/cjfas-20160050 . 
Schmid-Hempel, P., and Frank, S.A. 2007, October 26. Pathogenesis, virulence, and infective dose. Public Library of Science. doi:10.1371/journal.ppat.0030147.

Skarðhamar, J., Albretsen, J., Sandvik, A.D., Lien, V.S., Myksvoll, M.S., Johnsen, I.A., Asplin, L., Ådlandsvik, B., Halttunen, E., and Bjørn, P.A. 2018. Modelled salmon lice dispersion and infestation patterns in a sub-arctic fjord. ICES J. Mar. Sci. doi:10.1093/icesjms/fsy035.

Stene, A., Viljugrein, H., Yndestad, H., Tavornpanich, S., and Skjerve, E. 2014. Transmission dynamics of pancreas disease (PD) in a Norwegian fjord: Aspects of water transport, contact networks and infection pressure among salmon farms. J. Fish Dis. 37(2): 123-134. John Wiley \& Sons, Ltd (10.1111). doi:10.1111/jfd.12090.

Stucchi, D.J., Guo, M., Foreman, M.G.G., Czajko, P., Galbraith, M., Mackas, D.L., and Gillibrand, P.A. 2011. Modeling sea lice production and concentrations in the Broughton Archipelago, British Columbia. In: Salmon lice: An integrated approach to understanding parasite abundance and distribution. pp. 117-150.

Velentgas, P., Dreyer, N.A., Nourjah, P., Smith, S.R., and Torchi, M.M. 2013. US Department of Health and Human Services Developing a Protocol for Observational Comparative Effectiveness Research. A user's guide.. Available from www.effectivehealthcare.ahrq.gov [accessed 15 June 2019].

Wagner, G.N., Fast, M.D., and Johnson, S.C. 2008. Physiology and immunology of Lepeophtheirus salmonis infections of salmonids. Trends Parasitol. 24(4): 176-183. Elsevier Current Trends. doi:10.1016/J.PT.2007.12.010.

Wolff, E., Arnell, N., Friedlingstein, P., Gregory, J., Haigh, J., Haines, A., Hawkins, E., Hegerl, G., Hoskins, B., Mace, G., Prentice, I., Shine, K., Smith, P., Sutton, R., and Turley, C. 2017. The Royal Society Climate Updates: What have we learnt since the IPCC 5th Assessment Report? The Royal Society Policy Publication. Available from http://plymsea.ac.uk/7783/ [accessed 22 January 2019].

Wood, S. 2006. Generalized Additive Models: An Introduction with R. by S. N. WOOD. Book 63(4): 1298-1299. doi:10.1111/j.1541-0420.2007.00905_3.x. 
Table 1 The percent change in AUC from the "no biological model" simulation to the three simulations including all or some aspect of the biological model.

\begin{tabular}{cccc}
\hline & Maturation & Survivorship & Full bio model \\
\hline Sub-network 1 & 58.5 & 87.7 & 99.4 \\
Sub-network 2 & 40.8 & 87.9 & 99.3 \\
Sub-network 3 & 52.1 & 88.1 & 99.4 \\
Sub-network 4 & 68.2 & 80.1 & 99.8 \\
\hline
\end{tabular}

Table 2 Output for GAM models with more than one predictor with p-values $<0.15$, tried with multiple predictors together (the unconditional association of only river is also show in the table for comparison purposes between the models, and because sub-network 3 only had river as a significant predictor

\begin{tabular}{ccccc}
\hline Sub-network & Predictors & p-values & AIC & \% dev exp \\
\hline 1 & $\begin{array}{c}\text { River } \\
\text { RiverXwind }\end{array}$ & $\begin{array}{c}<0.001 \\
\text { Interaction }=0.09\end{array}$ & -791.00 & 56.1 \\
1 & & & & 58.6 \\
& River & $<0.001$ & -789.98 & \\
\hline 2 & windXtide & 0.002 & -671.39 & 64.2 \\
2 & riverXtide & 0.099 & -698.03 & 73.5 \\
2 & riverXwind & 0.147 & -700.92 & 71.5 \\
& & & & \\
\hline 3 & River & $<0.001$ & -998.20 & 72.3 \\
& & & & \\
\hline 4 & Heat & 0.002 & -1005.18 & 8.7 \\
4 & heatXwind & 0.135 & -1001.31 & 34.7 \\
\hline
\end{tabular}

Table 3 AUC for sensitivity analysis simulation plot.

\begin{tabular}{ccc}
\hline Simulation & AUC & $\begin{array}{c}\text { \% change from complete } \\
\text { (survivorship/maturation) } \\
\text { simulation }\end{array}$ \\
\hline Full bio model & 13.39 & - \\
$50 \%$ maturation & 1.55 & -88.42 \\
$150 \%$ maturation & 42.00 & 213.67 \\
$50 \%$ survivorship & 8.29 & -38.09 \\
$150 \%$ survivorship & 24.88 & 85.81 \\
\hline
\end{tabular}


Fig 1 Map of the study area, showing the locations of farms and approximate locations of major river mouths.

Fig 2 Connectivity plots for the entire network of farms, for four different simulations. Yellow points are the mean connectivity of the entire network for a given CRD, and yellow bars are standard deviations. The blue lines show GAM smoothers. a) Physical model, b) Survivorship only, c) Maturation only, d) Maturation and Survivorship. Note that the y-axes are on four different scales.

Fig 3 Connectivity plots for the simulation based on the full biological model (survivorship and maturation). a) Sub-network 1 (farms 1-5), b) Sub-network 2 (farms 6-7 and 16-18), c) Subnetwork 3 (farms 10-11 and 15), and d) Sub-network 4 (farms 8-9, 12-14, and 19-20).

Fig 4 Summary of the dependent variables in the GAM model. All panels show a rolling 11-day average to mimic the 11 days that each CRD represents. a) River discharge, summed from all 8 rivers $\left(\mathrm{m}^{3} \mathrm{~s}^{-1}\right)$. b) Heat flux, which was the same for the entire model domain (watts $\mathrm{m}^{-2}$ ). c) Tidal range, data taken from the Port Hardy weather station (m). d) Maximum wind gust in modelled winds, extracted from the 4 weather station locations used to force the physical model reported in Foreman et al, $2008\left(\mathrm{~ms}^{-2}\right)$. Plots showing the river discharge for each individual river and the wind gusts for each individual station can be found in the supplementary materials.

Fig 5 a) Mean salinity and, b) Mean temperature, for each cohort of particles, throughout the 11day simulation, shown in blue. The second y-axis shows the a) Instantaneous survivorship rate, and b) Instantaneous maturation rate produced by the mean salinity and temperature each cohort is experiencing for that day, shown as the black lines. The flat part of the black line in panel (a) over days 10-40 is due to the fact that instantaneous maturation is a constant when salinity $>31$, which occurred over these initial days of the simulation.

Fig 6 Smoothed plots for the GAMs. Each predictor (horizontal row) is shown for each subnetwork (vertical column), to provide a set of unconditional associations. a-d) are river discharge, e-h) are heat-flux, i-l) are wind, and m-p) are tide, (for sub-networks 1-4, respectively.)

Fig 7 A comparison between the simulated year (2009) and 41 years of historical data. The mean values for 2009 (red line) and for all 41 years (black line), together with the standard deviations over these years (in grey) are illustrated for: a) the mean daily river discharge, and, b) the cumulative averages over the period of the simulation. 


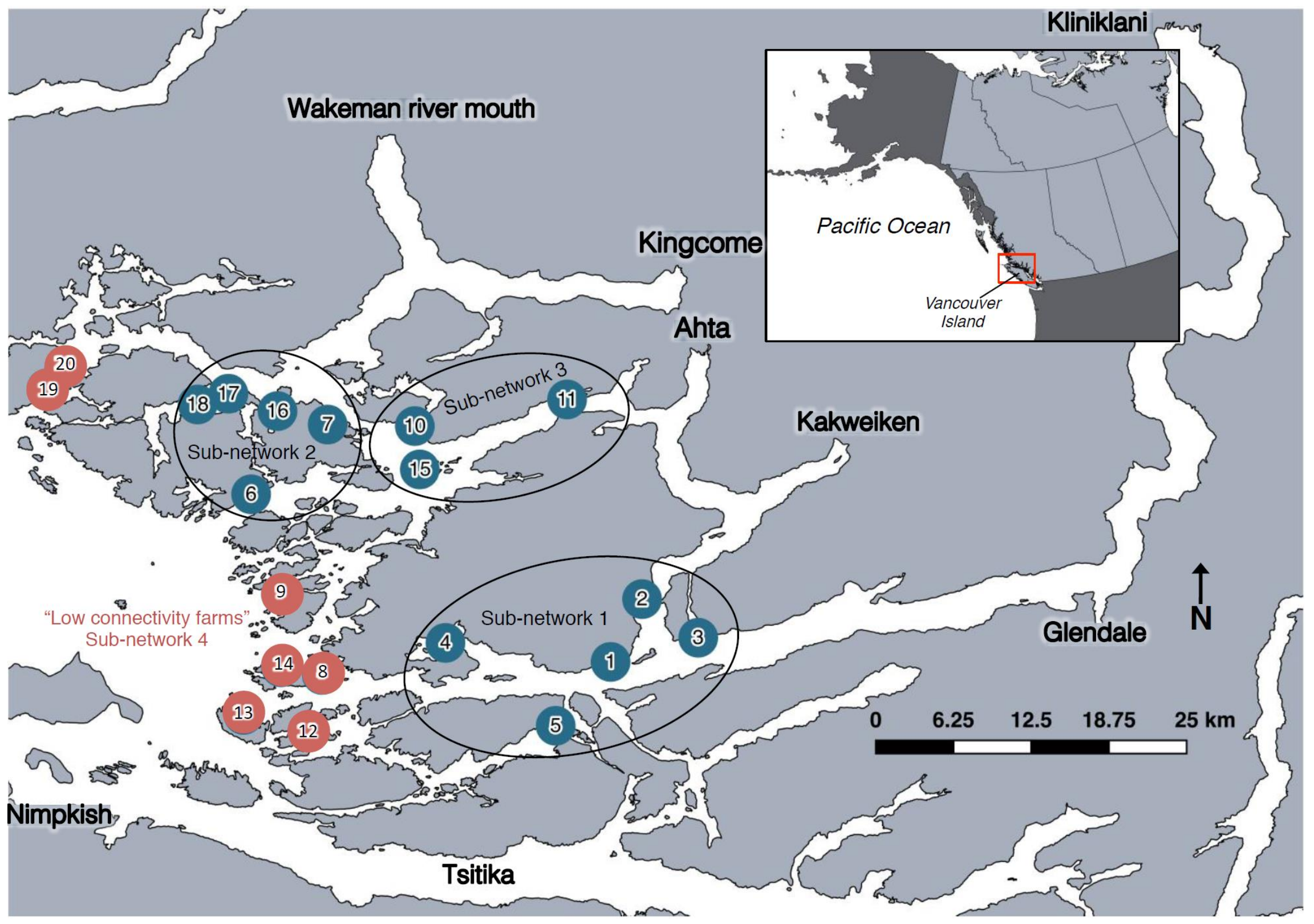




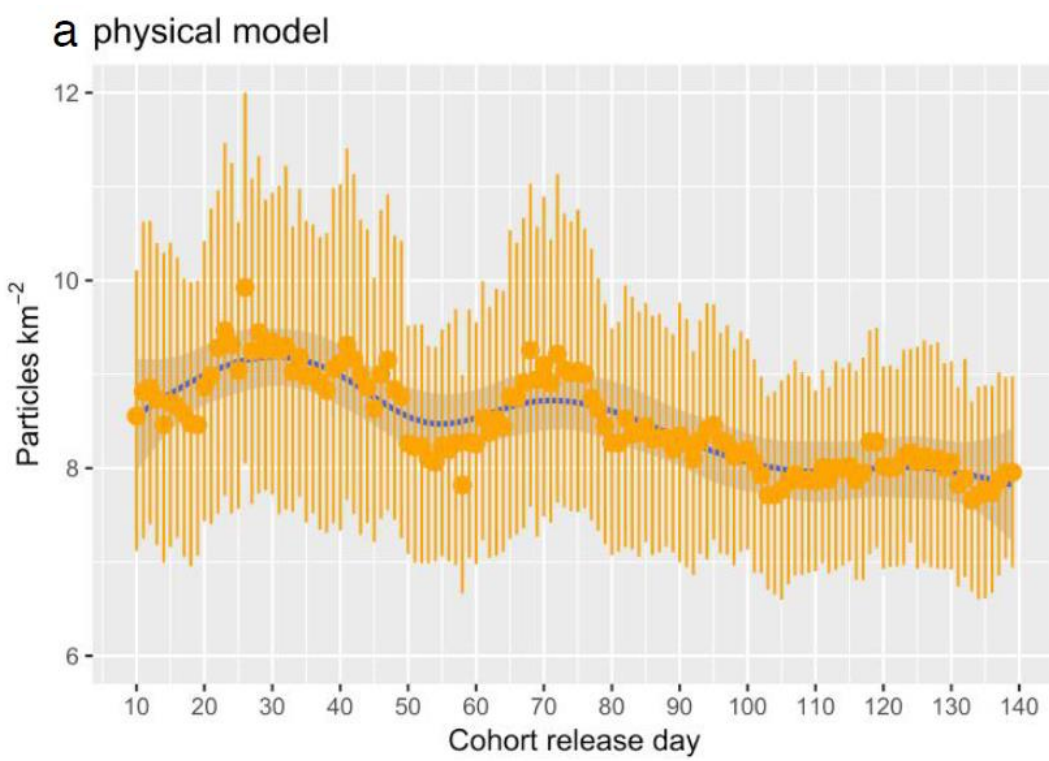

\section{C maturation only}

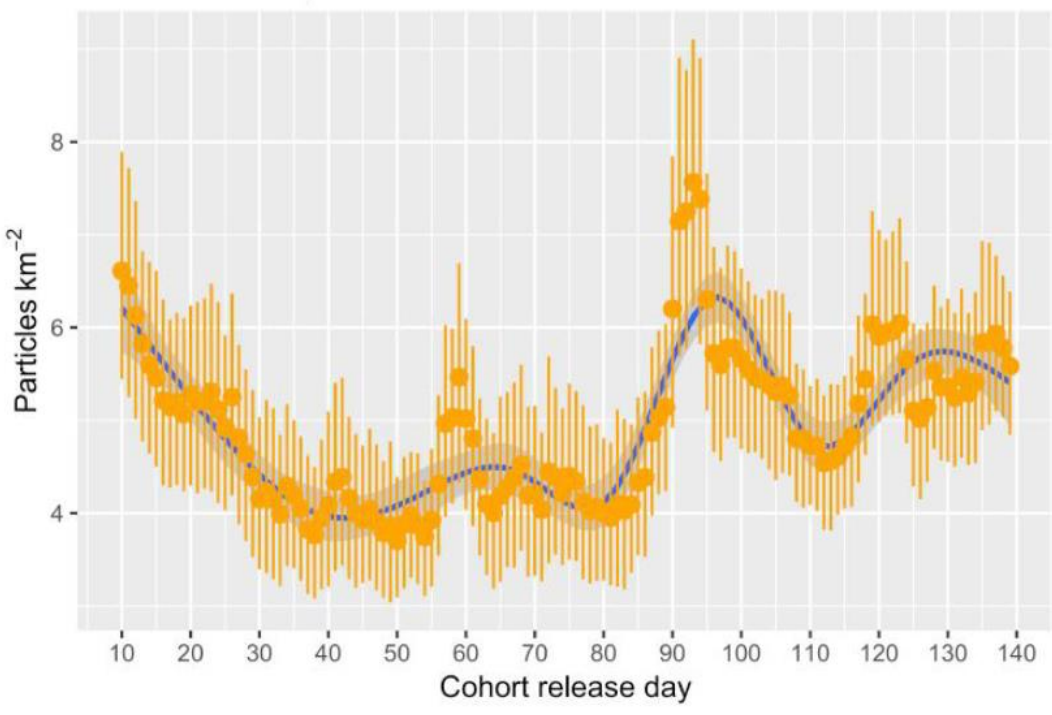

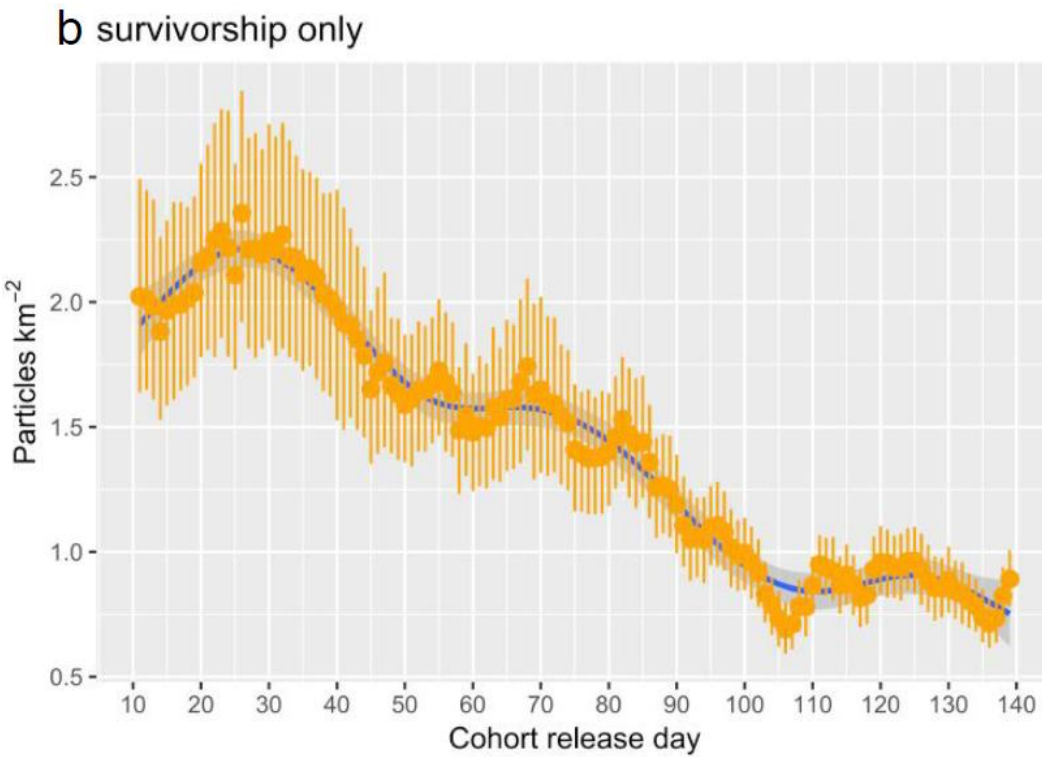

\section{$\mathrm{d}$ maturation and survivorship}

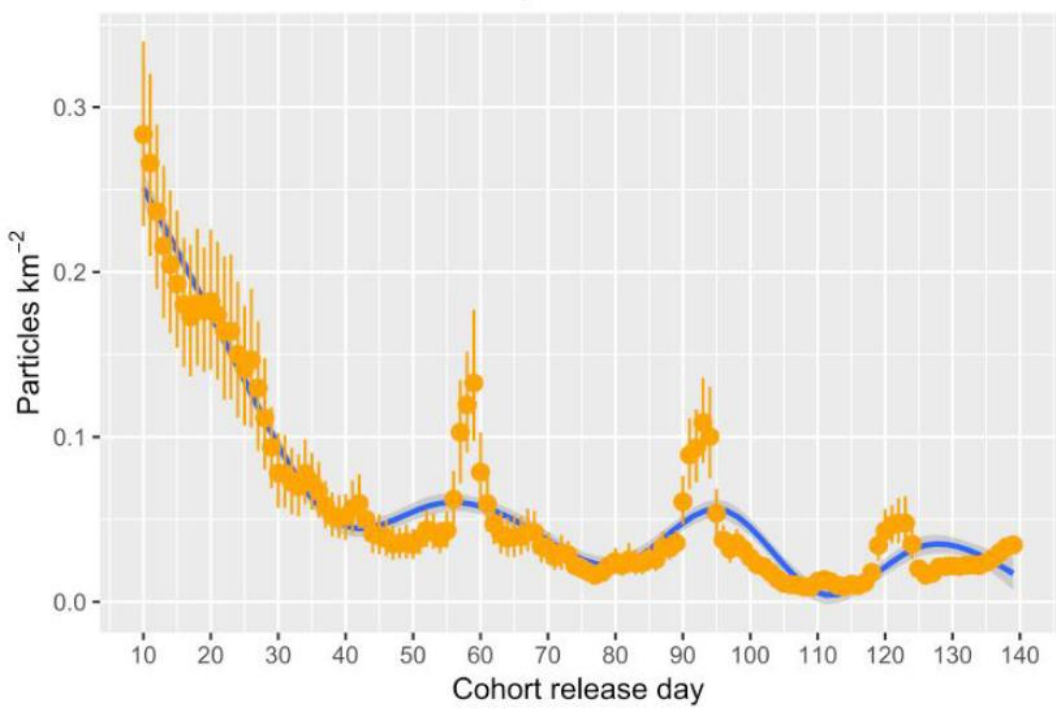



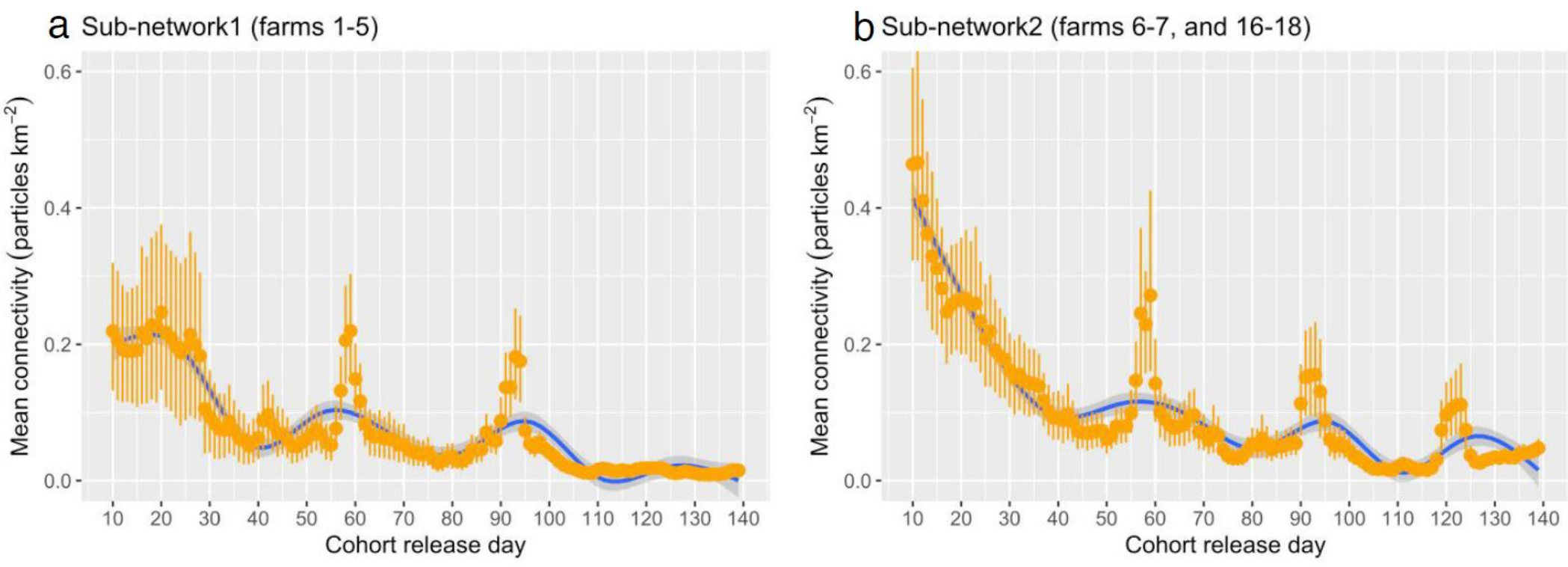

\section{Sub-network3 (farms 10-11 and 15)}
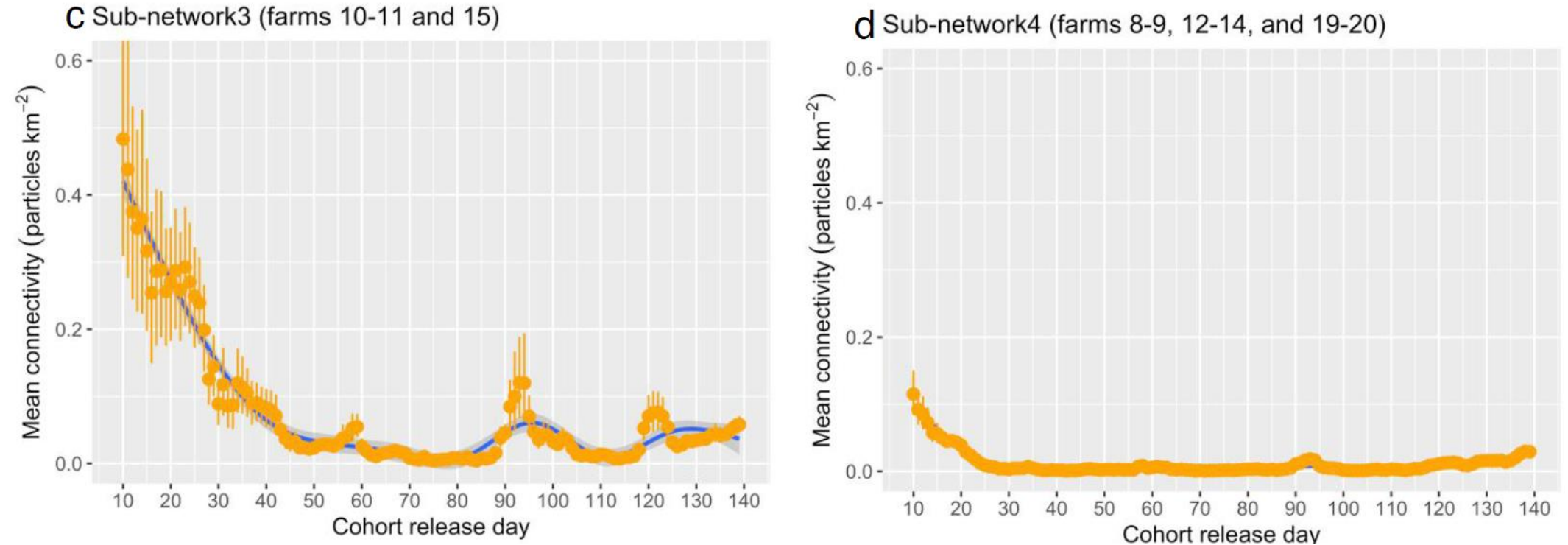

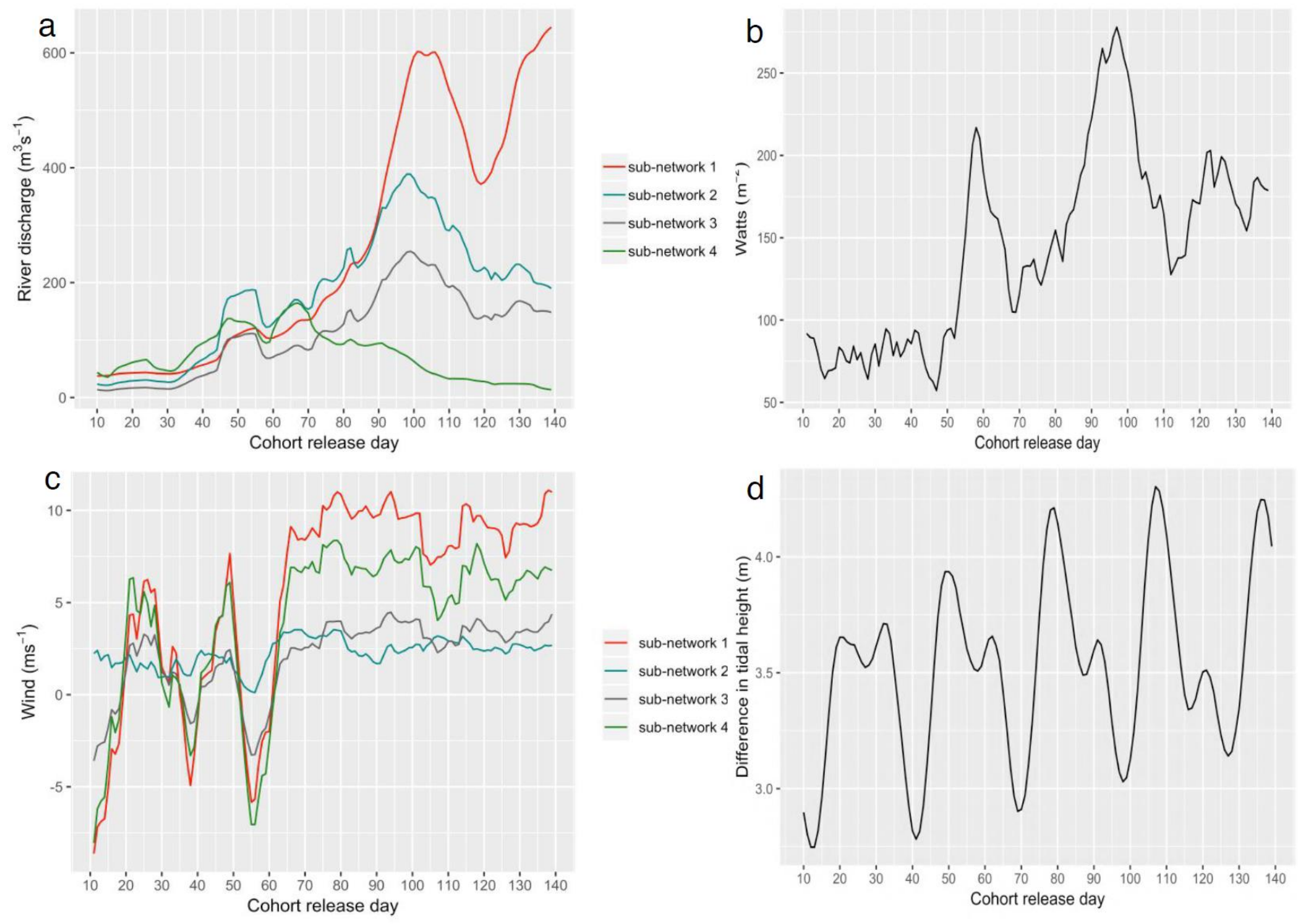

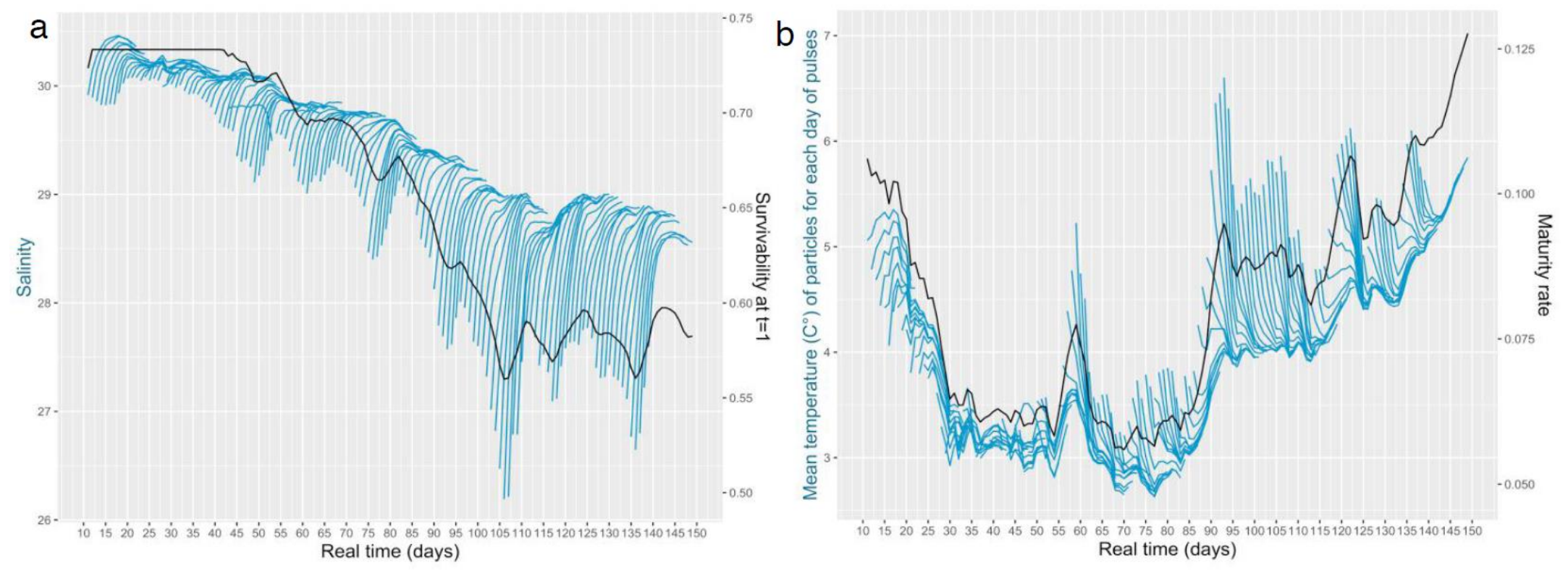

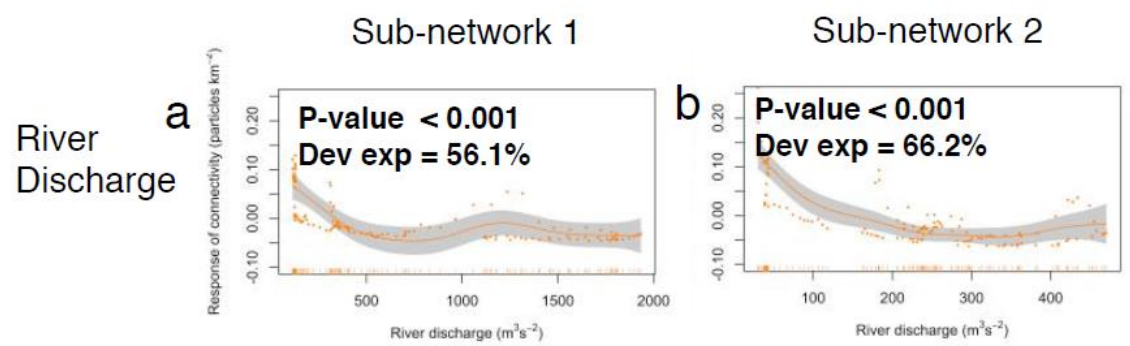

Sub-network 3

Sub-network 4
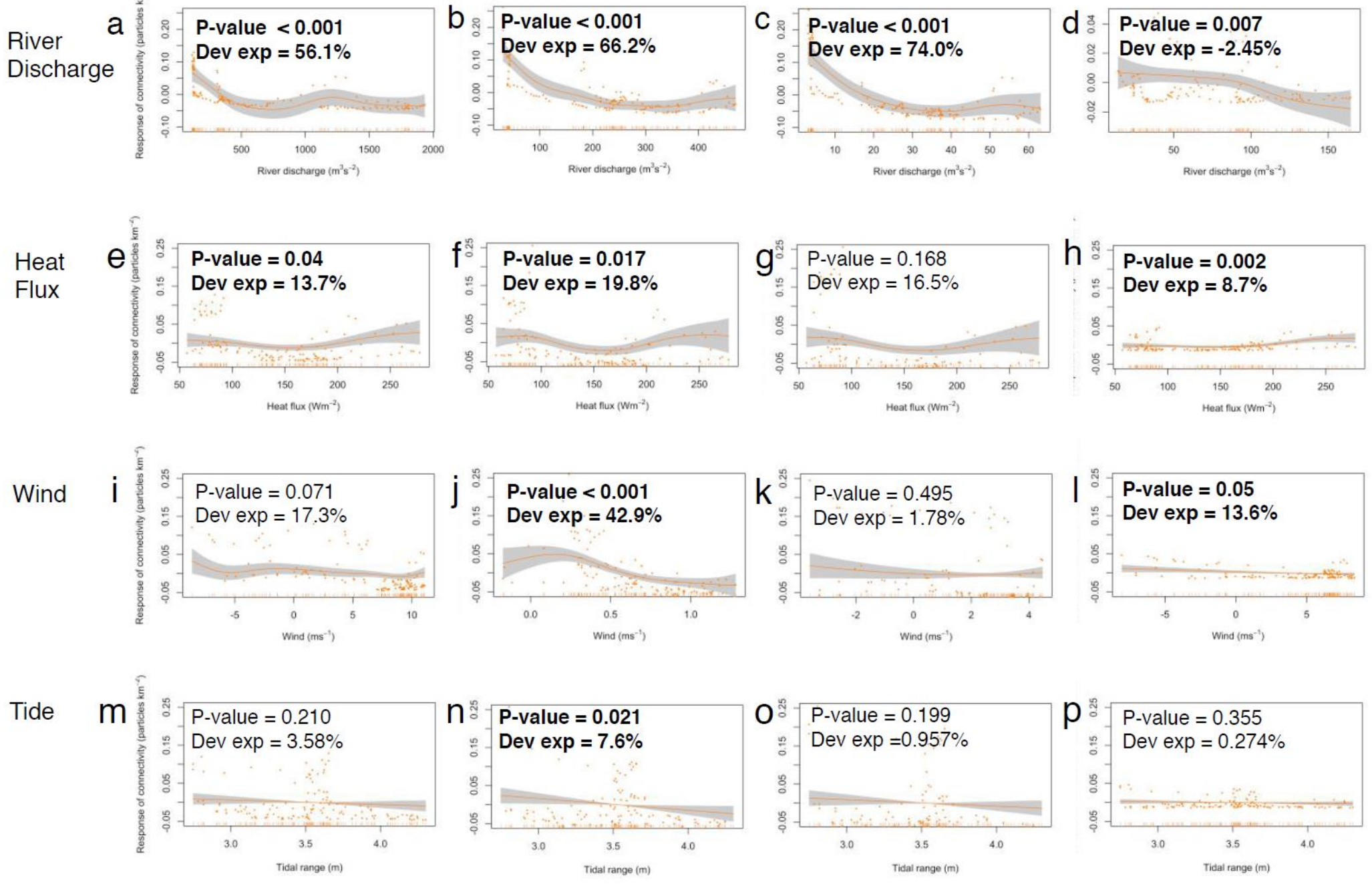

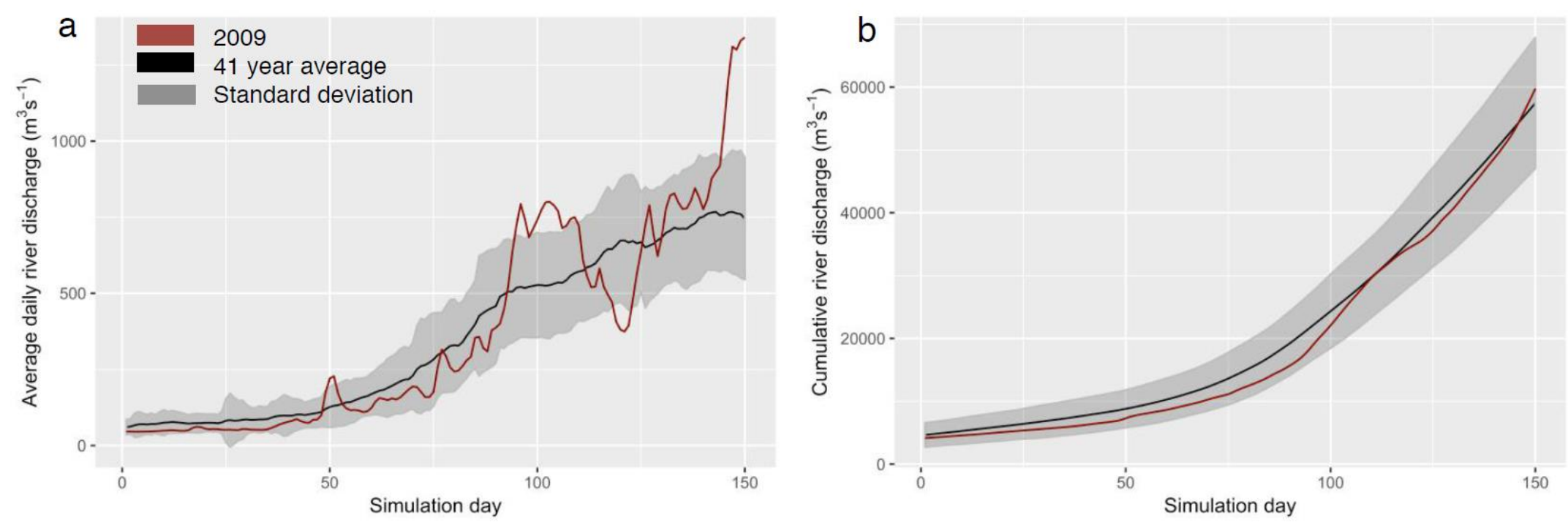